CNS Drugs 2013; 27 (2)

Review Article

Running title: Potential Mechanisms of Action of Lithium in Bipolar Disorder

\title{
Potential Mechanisms of Action of Lithium in Bipolar Disorder
}

\section{Current Understanding}

Gin S. Malhi ${ }^{1,2}$, Michelle Tanious ${ }^{1,2}$, Pritha Das ${ }^{1,2}$, Carissa Coulston ${ }^{1,2}$ and Michael Berk ${ }^{3-6}$

${ }^{1}$ Discipline of Psychiatry, Sydney Medical School, University of Sydney, Sydney, NSW, Australia

${ }^{2}$ CADE Clinic, Department of Psychiatry, Royal North Shore Hospital, St. Leonards, Sydney, NSW, Australia

${ }^{3}$ Deakin University, School of Medicine, Barwon Health, Geelong, VIC, Australia

${ }^{4}$ Orygen Youth Health Research Centre, Parkville, VIC, Australia

${ }^{5}$ Mental Health Research Institute, University of Melbourne, Kenneth Myer Building, Parkville, VIC, Australia

${ }^{6}$ University of Melbourne, Department of Psychiatry, Royal Melbourne Hospital, Parkville, VIC, Australia

Correspondence: Gin S. Malhi, CADE Clinic, Level 5, Building 36, Royal North Shore Hospital, St Leonards, Sydney, NSW 2065, Australia.

Email: gin.malhi@sydney.edu.au 
Fig. 1 Lithium actions. Lithium exerts its effects at multiple levels beginning with clinical changes to mood by counteracting mania and depression and diminishing suicidality. Evidence for the effects of lithium on cognition from neuropsychological and functional magnetic resonance imaging studies point overall towards cognitive compromise; however, evidence for this has been mixed. Structural imaging studies have provided evidence of neuroprotection with increased grey matter volumes in particular in the amydgala, hippocampus and prefrontal cortical regions in lithium-treated patients. Changes to neurotransmission that have clinical impact may be explained through increased inhibitory and decreased excitatory neurotransmission in lithium-treated patients. At the intracellular level, lithium influences second messenger systems, which modulate neurotransmission and facilitate cellular viability by promoting anti-oxidant defences, decreasing apoptosis and increasing neuroprotective proteins. $A C$ adenyl cyclase, $b c l$-2 B-cell lymphoma 2, BDNF brain-derived neurotrophic factor, $G S K$ glycogen synthase kinase, MARCKS myristoylated alanine-rich c kinase substrate, $P K C$ protein kinase $\mathrm{C}$, $\uparrow$ indicates increased, $\downarrow$ indicates decreased

Fig. 2 The actions of lithium on pre- and post-synaptic neurotransmission. The facilitatory actions of lithium are depicted in green, and its inhibitory actions in red. Lithium inhibits excitatory neurotransmission by decreasing pre-synaptic dopamine activity and inactivating post-synaptic Gproteins. It also exerts an inhibitory effect downstream on the AC system, and via effects on cAMP, modulates further neurotransmission. Similarly, lithium promotes inhibitory neutrotransmission through its modulation of glutamatergic neurotransmission by downregulating the NMDA receptor and inhibiting the $\mathrm{mI}$ second messenger system, which is responsible for maintaining signalling efficiency. When activated, the mI system leads to phosphorylation of PI, which in turn initiate two second messenger pathways involving DAG and $\mathrm{IP}_{3}$. These components of the phosphorylation cycle are responsible for modulating neurotransmission and regulating genetic transcription. Chronic modulation of this cycle through lithium exposure eventually alters gene transcription, which ultimately produces long-term changes in neurotransmission. Lithium additionally inhibits neurotransmission by facilitating the release of $\mathrm{GABA}$ and upregulating the $\mathrm{GABA}_{\mathrm{B}}$ receptor. $A C$ adenyl cyclase, $c A M P$ cyclic adenosine monophosphate, $D A G$ diaglycerol, $I P_{3}$ inositol triphosphate, $m I$ myo-inositol, $P I$ phosphoinositides, $\uparrow$ indicates increased, $\downarrow$ indicates decreased

Fig. 3 The effects of lithium on second messenger pathways. The inhibitory actions of lithium are depicted in red, and its facilitatory actions are depicted in green. (a) AC/cAMP system. Lithium modulates this system in several ways: initially, basal levels of AC and cAMP are increased. Consequently, when a cell is stimulated, large fluctuations of AC and cAMP that would normally occur 
are minimized, therefore stabilizing the system. The CREB transcription factor is an important downstream target of the AC system and is activated by lithium, which facilitates the production of neuroprotective factors including BDNF and bcl-2. (b) The PI cycle. Lithium inhibits the PI cycle: the PI cycle is activated following stimulation of the cell surface receptor by a neurotransmitter. PLC mediates the hydrolysis of $\mathrm{PIP}_{2}$ to the secondary messengers DAG and $\mathrm{IP}_{3}$. These then activate downstream signalling pathways. ImPase and IPPase facilitate recycling of $\mathrm{IP}_{3}$ back into $\mathrm{mI}$, which then allows the PI cycle to continue. Lithium inhibits cellular $\mathrm{mI}$ by: (1) blocking the reuptake of inositol via inhibition of the SMIT and (2) via direct inhibition of IPPase and ImPase. Overall, this results in the inhibition of transmembrane signalling and triggering of autophagy. (c) PKC, MARCKS, GSK-3: lithium inhibits PKC, MARKS and GSK-3: PKC and MARCKS are downstream targets of DAG, and thus direct inhibition by lithium reduces pre- and post-synaptic excitatory neurotransmission. GSK-3 plays a major role in cellular structure and resilience. Direct and indirect inhibition of this kinase by lithium activates the Akt neuroprotective pathway. (d) Autophagy: lithium ultimately inhibits this process. Autophagy is induced by the intracellular calcium released from the mitochondria by $\mathrm{IP}_{3}$. The mTOR protein is activated by lithium and is a negative regulator of autophagy and therefore inhibits this process. Lithiuminduced depletion of $\mathrm{IP}_{3}$ also induces autophagy; however, its inhibitory effects through the mTOR protein are more potent. $A C$ adenyl cyclase, $b c l$-2 B-cell lymphoma 2, $B D N F$ brain-derived neurotrophic factor, $c A M P$ cyclic adenosine monophosphate, $C R E B$ cAMP response element binding, DAG diaglycerol, GSK-3 glycogen synthase kinase 3, ImPase inositol monophosphate 1-phosphatase, IPPase inositol phosphate 1-phosphatase, $\mathrm{IP}_{3}$ inositol triphosphate, MARCKS myristoylated alanine-rich c kinase substrate, $m I$ myoinositol, mTOR mammalian target of rapamycin, $P I$ phosphoinositide, $P I P_{2}$ phosphoinositol 4-5-biphosphate, $P K C$ protein kinase C, $P L C$ phospholipase C, SMIT sodium myoinositol transporter 
Keywords: BDNF; Bipolar-disorders; Depression; Dopamine; Gamma-aminobutyric-acid; Lithium; Mania; Neuroprotection. 


\begin{abstract}
Lithium has been used for over half a century for the treatment of bipolar disorder as the archetypal mood stabilizer and has a wealth of empirical evidence supporting its efficacy in this role. Despite this, the specific mechanisms by which lithium exerts its mood-stabilizing effects are not well understood. Given the inherently complex nature of the pathophysiology of bipolar disorder, this paper aims to capture what is known about the actions of lithium ranging from macroscopic changes in mood, cognition and brain structure to its effects at the microscopic level on neurotransmission and intracellular and molecular pathways. A comprehensive literature search of databases including MEDLINE, EMBASE and PsychINFO was conducted using relevant keywords and the findings from the literature were then reviewed and synthesized. Numerous studies report that lithium is effective in the treatment of acute mania and for the long-term maintenance of mood and prophylaxis; in comparison, evidence for its efficacy in depression is modest. However, lithium possesses unique anti-suicidal properties that set it apart from other agents. With respect to cognition, studies suggest that lithium may reduce cognitive decline in patients; however, these findings require further investigation using both neuropsychological and functional neuroimaging probes. Interestingly, lithium appears to preserve or increase the volume of brain structures involved in emotional regulation such as the prefrontal cortex, hippocampus and amygdala possibly reflecting its neuroprotective effects. At a neuronal level, lithium reduces excitatory (dopamine and glutamate) but increases inhibitory (GABA) neurotransmission; however, these broad effects are underpinned by complex neurotransmitter systems that strive to achieve homeostasis by way of compensatory changes. For example, at an intracellular and molecular level, lithium targets secondmessenger systems that further modulate neurotransmission. For instance, the effects of lithium on the adenyl cyclase and phospho-inositide pathways as well as protein kinase $\mathrm{C}$ may serve to dampen excessive excitatory neurotransmission. In addition to these many putative mechanisms, it has also been proposed that the neuroprotective effects of lithium are key to its therapeutic actions. In this regard, lithium has been shown to reduce the oxidative stress that occurs with multiple episodes of mania and
\end{abstract}


depression. Further, it increases protective proteins such as brain-derived neurotrophic factor and B-cell lymphoma 2 and reduces apoptotic processes through inhibition of glycogen synthase kinase 3 and autophagy. Overall, it is clear that the processes that underpin the therapeutic actions of lithium are sophisticated and most likely inter-related. 


\section{Introduction}

Lithium, introduced 60 years ago by John Cade for the treatment of bipolar disorder, remains a first-line option because of its efficacy in long-term mood stabilization, which is supported by a wealth of empirical evidence and clinical experience ${ }^{[1,2]}$. Lithium has also been shown to significantly reduce the risk of suicide, and this unique property sets it apart from other medications used for the treatment of bipolar disorder ${ }^{[3-5]}$. Interestingly, however, the mechanisms by which lithium exerts its putative clinical effects are largely unknown. Difficulty in defining bipolar disorder on the basis of clinical phenomenology has undoubtedly contributed to this nescience. Conversely, it could be argued that excellent lithium response is one of the best biomarkers available, and that it may be more fruitful to examine clinical features and biomarkers in this treatment-sensitive subgroup; however, this kind of approach is not consistent with the current DSM-driven zeitgeist. Further, the underlying pathophysiology of bipolar disorder is likely to be highly complex, involving many interacting neurotransmitter systems and neuronal circuits within the brain ${ }^{[6]}$.

Research into the mechanism of action of lithium has been conducted at multiple levels, ranging from macroscopic changes in clinical symptoms and brain structure to alterations at the cellular and intracellular levels. In order to conceptualize these levels, Fig. 1 provides an overview of what is currently known about the effects of lithium. Macroscopically, lithium produces clinical changes in mood and cognition, and can alter brain structure. In contrast, microscopically lithium targets cellular, intracellular and molecular processes. For example, lithium modulates neuronal function, by decreasing excitatory neurotransmission through glutamate and dopamine, and increasing inhibitory neurotransmission via $\mathrm{GABA}^{[7]}$. At the intracellular and molecular levels, lithium alters the second messenger systems that operate within neurons such as inositol, diaglycerol (DAG), protein kinase C (PKC), intracellular calcium and myristoylated alanine-rich C kinase substrate (MARCKS), which ultimately alter neurotransmission 
(sending and receiving signals), and promote cellular viability. Such processes are complex and involve a number of different proteins.

Fig. 1 also shows that lithium has notable protective effects that occur at multiple levels. Increasingly, bipolar disorder is being recognized as a degenerative process, ${ }^{[8]}$ whereby disease-related stressors such as excitotoxicity lead to apoptosis, which produces atrophy of multiple brain regions. In this regard, lithium has been shown to increase cellular longevity by cessating or abating apoptosis, known as neuroprotection ${ }^{[9]}$. At the same time lithium has also been shown to promote the generation of new cells, referred to as neuroproliferation ${ }^{[8,10,11]}$, and lastly, lithium is able to interrupt the cascade of neurotoxic processes that lead to tissue vulnerability and progressive brain and functional change, known as neuroprogression ${ }^{[12]}$. This paper therefore briefly elaborates upon our current understanding of the potential mechanisms through which lithium produces its broad range of actions in the context of bipolar disorder pathophysiology.

A comprehensive literature search of peer-reviewed publications, written in English but not limited by date, was conducted using MEDLINE, EMBASE and PsychINFO. Specifically, keywords that were used to identify relevant articles included 'bipolar disorder', 'lithium', 'mechanisms of action', 'therapeutic actions', 'efficacy', 'anti-suicidal', 'neuroprotection', 'neuroprogression', 'brain structure', 'functional magnetic resonance imaging', ‘neuropsychology', ‘neurocognition', ‘cognition', 'neurotransmission', 'dopamine', 'glutamate', 'gamma-aminobutyric acid', 'NMDA', 'G-protein', 'second messenger systems', 'adenylyl cyclase', 'phosphoinositide', 'inositol', 'protein kinase C', 'myristoylated alanine-rich C kinase substrate', 'intracellular calcium', 'brain derived neurotrophic factor', 'apoptosis', 'oxidative stress', 'mitochondria', 'bcl-2', 'glycogen synthase kinase 3' and 'autophagy'. Relevant findings were then identified and synthesized in combination with additional literature known to the authors. 


\section{Clinical Changes to Mood}

\subsection{Acute Mania}

Clinical trials over recent decades have consistently demonstrated that lithium is effective for the treatment of acute mania ${ }^{[13]}$, with several randomized controlled trials providing robust evidence of its superiority in the treatment of acute mania when compared with mood stabilizers (valproate) ${ }^{[14,15]}$, neuroleptics (olanzapine and risperidone) $)^{[15-17]}$ or placebo ${ }^{[2,4,15,18,19]}$. Although a recent meta-analysis has suggested that neuroleptics are superior to mood stabilizers including lithium ${ }^{[20]}$, the findings have been questioned as the meta-analysis only investigated a short-term outcome ( 3 weeks), and it is important to consider how these results would change for long-term treatment ${ }^{[21]}$.

Nevertheless, lithium monotherapy remains a first-line option for acute mania in clinical practice guidelines ${ }^{[4,22-25]}$. When administered alone, lithium can take up to 6-10 days to relieve manic symptoms and therefore in practice it is often combined with a neuroleptic to achieve faster symptom relief ${ }^{[2,4,26]}$.

\subsection{Acute Depression}

The evidence for lithium in the treatment of bipolar depression is less impressive than for acute mania, with recent clinical trials failing to demonstrate significant superiority compared with other agents or placebo $^{[27-29]}$. There are several reasons for this. First, the antidepressant effect of lithium has a considerable time lag, usually 6-8 weeks, hence lithium may be perceived by patients as not being efficacious, resulting in high drop-out rates in clinical trials that can skew results ${ }^{[30]}$. Second, the psychological and social reasons for depression are often more complex than those for mania ${ }^{[18]}$, hence study samples are inevitably more heterogeneous. Indeed, recent reviews on the treatment of bipolar depression using lithium have recognized the paucity of well controlled randomized trials and this limits the ability to use meta-analytical techniques to evaluate its efficacy ${ }^{[28,31]}$. Despite this, lithium is still 
recommended by current clinical practice guidelines for the treatment of bipolar depression ${ }^{[31-33]}$, in particular bipolar I. This is partly because fewer studies have examined other 'subtypes' of bipolar disorder but also because lithium appears to be most effective in bipolar disorder with recognizable episodes of mania and depression where periods of illness are recurrent and separated clearly by periods of remission $^{[18]}$.

\subsection{Maintenance and Prophylaxis}

The evidence for the efficacy of lithium in the maintenance of euthymia and prophylaxis of mania, depression and suicidal behaviours has been robustly supported ${ }^{[4,34,35]}$, and its real world effectiveness has been demonstrated in the recent BALANCE (Bipolar Affective Disorder: Lithium/Anti-Convulsant Evaluation) study ${ }^{[36]}$. Meta-analytical reviews have shown that lithium reduces the risk of a manic relapse by between $40 \%$ and $61 \%$ and the risk of relapse for depression by approximately $22 \%{ }^{[19]}$. Furthermore, in $60-80 \%$ of patients, the abrupt cessation of lithium, or a rapid reduction in its plasma concentrations, precipitates relapse, underscoring its importance in maintenance therapy ${ }^{[23,37-40]}$. Interestingly, however, there is some evidence that shows that lithium has comparable efficacy to valproate ${ }^{[41]}$.

\subsection{Anti-Suicidal Properties}

Bipolar patients are at a tenfold increased risk of suicide or suicide attempts as compared with the general population $^{[3]}$, and this contributes significantly to their increased mortality rate ${ }^{[37]}$. One of the key attributes of lithium is its 'anti-suicidal' effect ${ }^{[3-5,18,42,43]}$. Patients that adhere to lithium treatment show a reduction in suicidal behaviour ${ }^{[37]}$ even when it has not been efficacious in achieving mood stabilization $^{[44]}$. Indeed, evidence shows that the risk of suicide in lithium-treated patients is six times less than patients not taking lithium ${ }^{[3]}$, and that the risk of death by suicide, as well as the risk of self-harm, is

reduced by $60 \%$ and $70 \%$, respectively ${ }^{[5,45]}$. It is thought that lithium achieves these anti-suicidal effects by reducing impulsivity and aggression; however, the precise mechanism of its anti-suicidal action requires further investigation ${ }^{[3,18,34]}$. 


\subsection{Summary}

Lithium is a unique therapeutic agent and arguably the only true mood stabilizer in the management of bipolar disorder. It has held pole position for more than half a century and is especially effective in treating acute mania and providing long-term prophylaxis. Its profound anti-suicidal properties further justify its use in bipolar disorder.

\section{Cognition}

\subsection{Neuropsychological Findings}

Cognitive changes occur at the endpoint of the process of neuroprogression, so consequently, studying the role of lithium on cognition opens a window to understanding its neuroprotective potential. Neuropsychological effects of lithium provide additional insight into the brain regions that lithium targets, via its observed impact on cognitive functions. A recent, rigorous meta-analysis on the effects of lithium on cognition was performed by Wingo and colleagues ${ }^{[46]}$ and based on 12 studies. Six of these studies were conducted on healthy volunteers, comprising 213 subjects in total, of whom 105 were exposed to lithium for a duration of 1-4 weeks. The other six studies were conducted on a total of 326 euthymic patients with affective disorders, of whom 171 were taking lithium. Analysis of the healthy subjects revealed no effects of lithium on any of the cognitive domains including immediate verbal learning and memory, attention, processing speed and executive functions. The cognitive effects of lithium among the affective disorder patients included impairments in immediate verbal learning and memory, creativity (comprising measures of verbal generativity) and more pronounced impairments on psychomotor performance. The authors concluded that these effects were a function of the duration of treatment rather than serum concentrations ${ }^{[46]}$.

The findings of these neurocognitive impairments with lithium use appear to be in accordance with preliminary data from functional magnetic resonance imaging (fMRI) studies (Sect. 3.2), but are difficult 
to disentangle from the processes of the illness itself, or reconcile with its purported neuroprotective properties (Sect. 3.1 and Sect. 6.2). This further highlights that the exact mechanism and targets of lithium action are not well understood, and that lithium possibly acts on a variety of molecular targets that can produce a range of effects ${ }^{[46]}$.

However, one of the main limitations of the studies that have been reviewed is that they mostly employ a cross-sectional design. In contrast to the results from the meta-analysis described above, other studies in which a longitudinal (and hence more rigorous) approach was undertaken have shown that memory is relatively unchanged with lithium therapy ${ }^{[47,48]}$. Furthermore, hypothyroidism, a common adverse effect of lithium, may have negative effects on cognition. Interestingly, however, studies rarely measure or control for its potential effects making it difficult to determine the extent of neurocognitive impairment associated with lithium ${ }^{[49]}$.

In complicating matters further, there is also evidence of improved cognition in lithium-treated patients. For example, the incidence of dementia has been shown to be decreased in bipolar disorder patients who have been taking lithium ${ }^{[50]}$. Further, a naturalistic study on cognition in bipolar disorder over 2 years reported that both at baseline and end-point lithium was associated with better psychomotor speed, although basic information processing was worse after 2 years. In this study, post hoc analysis also revealed that lithium positively predicts improvements in verbal learning, and negatively predicts deterioration in verbal memory ${ }^{[51]}$. Interestingly, another study found better executive functioning in bipolar disorder patients who were responsive to lithium as compared with lithium non-responders, suggesting that stabilization of mood may possibly be associated with preserved executive functions ${ }^{[52]}$. In aggregate, it does not appear possible to make definitive conclusions regarding the cognitive potential of lithium based on the existing evidence base. 


\subsection{Functional Neuroimaging Findings}

There is a lack of functional neuroimaging studies that identify neural networks modulated by lithium. This is perhaps because imaging modalities such as positron emission tomography and single photon emission computed tomography require specific molecular targets within the brain ${ }^{[53]}$, for which there are no known specific targets for lithium. In contrast, functional MRI studies can investigate the effects of lithium on neural networks by targeting blood flow changes within the nodes of these networks. However, most studies in bipolar disorder have primarily focused on understanding the effects of manic or depressed mood states on neural functioning, and only a few studies have examined the mood-stabilizing properties of lithium. Interestingly, studies examining the latter have been conducted by a single group. In a series of experiments looking at the effects of lithium on cognition, they found that its effect is both

mood state and task dependent ${ }^{[54-56]}$. Together, these studies suggest that in the presence of pathology, lithium administration augments cognitive functioning. However, conclusions from these studies need replication and should be treated as preliminary given the small sample sizes. Of note, in keeping with these findings in humans, a recent review of the effects of lithium on cognition in rat models concluded that the benefits to cognitive functioning are only seen in the presence of neurochemical or neurodegenerative insults, suggesting that the "neuroprotective action (of lithium) is translatable to functional improvement of compromised cognitive functioning"[57].

\subsection{Summary}

Neuropsychological research is equivocal with regard to the effects of lithium on cognition and evidence from functional neuroimaging though emergent is at present inconclusive. One important aspect that has recently come to light is that lithium possibly preserves cognitive functioning but only in the presence of pathology.

\section{Brain Structure}

\subsection{Neuroimaging Findings}


Studies investigating brain structure have implicated both cortical and subcortical brain regions in the pathology of bipolar disorder, but these findings depend on many factors such as the population (adult/adolescents) studied, severity of illness (number of episodes) as well as the region of interest, which makes the evidence difficult to evaluate ${ }^{[58,59]}$. Recent appraisals of the literature point toward regionally specific areas of abnormalities involving structures in the fronto-limbic network, which has implications for cognition and mood regulation ${ }^{[58,60]}$. Among subcortical regions that have primarily been implicated in bipolar disorder in adults, because of volumetric changes, are the hippocampus ${ }^{[61,62]}$, $\operatorname{amygdala}^{[63,64]}$ and striatum ${ }^{[65]}$ of which the latter two are also altered in adolescents with the disorder ${ }^{[66]}$. Furthermore, changes in the striatum appear to be related to the number of previous episodes ${ }^{[67]}$.

Grey matter volume reductions have been found in the subgenual ${ }^{[68]}$ and anterior cingulate cortex ${ }^{[69,70]}$. Reductions have also been observed in the dorsomedial and left parietal prefrontal cortex in depressed bipolar disorder patients ${ }^{[71]}$. These reductions in the prefrontal cortex have been attributed to diseaserelated stressors such as glutamate-induced excitotoxicity and subsequent oxidative stress ${ }^{[72]}$, which is reflected in the reduced neuronal densities in this area ${ }^{[73,74]}$. Conversely, not all studies have found a difference between bipolar disorder patients and healthy controls in the subgenual ${ }^{[75]}$ and anterior cingulate corte ${ }^{[76]}$. However, it has been shown that the rate of grey matter volume reduction is more rapid in bipolar disorder patients compared with controls despite a lack of difference in grey matter volumes between the groups ${ }^{[77]}$. Together this has led researchers to conceptualize bipolar disorder as a neurodegenerative process (specific models of degeneration are discussed later in Sect. 6.2).

Total or regional changes in grey matter volume have been found to be 'prevented' by the use of lithium. Lithium-treated patients compared with non-treated patients or healthy controls, show increases in total ${ }^{[59}$, ${ }^{78,79]}$ and regional grey matter volume. Regions that have shown improvement include the anterior 
cingulate, ventral prefrontal cortex, paralimbic association $\operatorname{cortex}^{[78,80]}$, superior temporal gyri ${ }^{[81]}$, left $\operatorname{amygdala}^{[82,83]}$ and hippocampus ${ }^{[61,84-86]}$. Notably these regions are part of the fronto-limbic network. A recent longitudinal study has shown an association between an increase in prefrontal grey matter volume with lithium responsiveness ${ }^{[87]}$, and in rats, the chronic administration of lithium has been shown to promote proliferation of neurons in the hippocampus ${ }^{[11]}$. These findings point to the potential neuroprotective effects of lithium ${ }^{[59]}$.

\subsection{Summary}

The neuroprotective and neuroproliferative effects of lithium in bipolar disorder patients have been demonstrated through preservation of grey matter volume compared with patients not treated with lithium and healthy controls. The mechanisms and significance of these changes however is not fully understood.

\section{Neurotransmission}

The limbic system subserves emotion, sleep, arousal and sexual function and has therefore been a focus of research into the pathophysiology of bipolar disorder and the action of mood stabilizers such as lithium. Early research in this area was greatly influenced by the monamine hypothesis of depression that was proposed almost half a century ago ${ }^{[88]}$. Consequently, initial bipolar disorder studies focussed on dopaminergic ${ }^{[89]}$ and serotonergic neurotransmitter systems, ${ }^{[90]}$ which have been useful but not sufficient in explaining the effects of lithium. With advances in science and technology and a greater understanding of neurotransmission, researchers have focussed increasingly on additional neurotransmitters, signal transduction pathways and second messenger systems ${ }^{[91]}$.

At the neuronal level, lithium acts both pre- and post-synaptically to modulate neurotransmission, and amongst the many neurotransmitters that have been investigated, it is the modulation and regulation of dopamine, glutamate and GABA that has provided useful insights (Fig. 2). 


\subsection{Dopamine and G-protein Coupled Receptors}

Dopamine is an excitatory neurotransmitter that plays a central role in the pathophysiology of bipolar disorder. A ‘cyclical dysregulation' of dopamine transmission has been hypothesized. During mania, dopamine neurotransmission is elevated and this prompts secondary homeostatic downregulation that eventuates in decreased neurotransmission and this is associated with clinical depression ${ }^{[92]}$. While there is good evidence for the role of dopamine in mania that is in keeping with this model, for example, dopamine precursors and agonists can induce mania in healthy individuals ${ }^{[93,94]}$ and levels of dopamine are elevated in both patients with mania ${ }^{[95]}$ and in animal models of mania ${ }^{[96]}$, its role in depression is less clear $^{[93]}$

Animal studies involving lithium-treated rats have found the levels of extraneuronal dopamine to be lower and this is associated with reduced reactivity to harmful stimuli ${ }^{[97,98]}$. However, other studies have found that the basal level of extraneuronal dopamine is unaffected by lithium treatment ${ }^{[99,100]}$.

Clinically, in patients, a lack of adherence to lithium treatment can cause therapeutic concentrations to drop and this increases the risk of relapse ${ }^{[101]}$. Hence, the effect of lithium withdrawal on dopamine levels has also been investigated albeit with conflicting results. One study in rats has shown that when dopamine re-uptake in the brain is inhibited, dopamine levels increase following lithium withdrawal and remain elevated for 3 days when compared with levels in rats that continued receiving lithium ${ }^{[100]}$. This potentially explains the recurrence of symptoms in patients following withdrawal. However, in a similar experiment, this same research group also found that rat brain dopamine levels remained lower for 3 days following lithium withdrawal as compared with rats not taking lithium, which suggests that the effects of

lithium can persist for a short time ${ }^{[99]}$. While there are methodological differences between the studies, the 
findings highlight the fact that the effect of lithium on dopamine neurotransmission is complex and possibly occurs at several levels.

The post-synaptic actions of dopamine are mediated via G-protein coupled receptors (Fig. 2). These protein receptors then stimulate second messenger systems such as adenyl cyclase (AC) and cyclic adenosine monophosphate (cAMP), which subsequently modulate neurotransmission (see discussion in Sect 6.1). Increased receptor and G-protein coupling has been shown in post-mortem studies of patients with bipolar disorder compared with age-matched controls. Further, particular subunits of the dopamineassociated G-protein have been reported to be higher in bipolar disorder patients, and may contribute to the pathology of bipolar disorder by altering subsequent biochemical pathways. Research has suggested that chronic lithium administration alters the functionality of these subunits, specifically the equilibrium between the active and inactive subunits, but does not change the levels of G-proteins per se ${ }^{[102]}$.

\subsection{Glutamate and NMDA receptors}

Glutamate is a stimulatory neurotransmitter that is elevated during mania ${ }^{[103]}$, and therefore glutamate neurotransmission is a reasonable target for mood stabilizers ${ }^{[104,105]}$.The NMDA glutamate receptor is structurally complex and implicated in a number of psychiatric disorders. Magnesium binds to sites on the NMDA receptor and this prevents its activation, but when glutamate and glycine bind to the receptor simultaneously, magnesium is displaced so that the receptor can be activated ${ }^{[106]}$. Lithium competes with magnesium at this binding site, and acutely stimulates the NMDA receptor, which in turn increases the availability of glutamate in the post-synaptic neuron ${ }^{[107]}$. However, with chronic lithium administration, glutamate neurotransmission stabilizes as the NMDA receptor is downregulated and this increases glutamate re-uptake, which restores glutamate transmission. This is one possible mechanism through which lithium achieves its long-term mood-stabilizing effect as well as its anti-manic properties ${ }^{[108-110]}$. Of note, the effects of lithium on glutamatergic neurotransmission appear to be specific to lithium, as other 
monovalent ions such as rubidium and caesium, as well as common antidepressants have failed to show similar effects ${ }^{[111]}$. Also, the ability of lithium to modulate glutamate transmission through the inhibition of the NMDA receptor-mediated calcium influx, reduces glutamate-induced excitation and thus demonstrates its neuroprotective potential ${ }^{[12,113]}$.

Of note, however, is that NMDA receptor activation is complex and is also influenced by other neurotransmitter systems, which are altered by lithium. For instance, chronic lithium administration enhances serotonergic neurotransmission by facilitating the post-synaptic serotonin $5-\mathrm{HT}_{1 \mathrm{~A}}$ receptor, which in turn inactivates the NMDA receptor ${ }^{[108]}$. Similarly, lithium has been shown to reduce dopamine activity (see previous discussion in Sect 5.1), and since dopamine normally increases NMDA receptor activity via dopamine $\mathrm{D}_{1}$ receptors, this is also decreased by the actions of lithium on dopamine ${ }^{[108]}$.

\subsection{GABA and GABA receptors}

GABA is an inhibitory neurotransmitter ${ }^{[114]}$ that plays a crucial role in modulating both dopamine and glutamate neurotransmission $^{[115]}$, and hence it is also thought to play a key role in mood stabilization ${ }^{[108,}$ ${ }^{114-116]}$. Patients with mood disorders, in particular bipolar disorder, have diminished GABA-ergic neurotransmission ${ }^{[114-118]}$. Hence, some researchers have suggested that low GABA plasma levels may be used as a marker of bipolar disorder ${ }^{[119]}$.

Low GABA levels result in an increase in excitatory neurotransmission that leads to excitatory toxicity and in turn causes apoptosis and cell $\operatorname{loss}^{[72]}$. In this context, lithium promotes the release of neuroprotective proteins and decreases the levels of pro-apoptotic proteins ${ }^{[120]}$. Lithium increases the level of GABA in the plasma and cerebrospinal fluid of humans as that of rats ${ }^{[110,121,122]}$. Interestingly, an 
increase in GABA in response to lithium reduces the level of glutamate and this downregulates the NMDA receptor ${ }^{[108]}$.

\subsection{Summary}

It is important to note that whilst specific neurotransmitter systems have been strongly implicated in the pathophysiology of bipolar disorder, these systems are highly interconnected via complex neural

networks ${ }^{[102]}$. In addition, the cellular mechanisms responsible for the mediation of neurotransmission are also implicated in bipolar disorder and therefore abnormalities in any of these systems, especially those with connections to the limbic system of the brain may result in symptoms ${ }^{[123]}$. However, there are significant gaps in our current understanding of many neurotransmitter systems and because lithium has multiple interacting targets across a number of neurotransmitter and non-transmitter systems, more integrated investigations are required to unravel the complexity of the actions of lithium on neurotransmission.

\section{Cellular Mechanisms}

\subsection{Second Messenger Systems}

Second messenger systems comprise enzymes and molecules that 'translate' signals received by receptors at the cell surface following activation by neurotransmitters to an intra-cellular response. This process of information transfer is called signal transduction and results in both short-acting and long-lasting responses. For example, ion channel phosphorylation is immediate, whereas modification of gene transcription takes much longer. Further complexity arises because cells can respond differentially to the same excitatory or inhibitory stimuli ${ }^{[124]}$. Lithium affects many of the enzymes and ions within these second messenger systems (see Table 1 and Fig. 3) and therefore investigation of these downstream targets of neurotransmission is essential to understanding its therapeutic effects. 
Like sodium $\left(\mathrm{Na}^{+}\right)$, lithium $\left(\mathrm{Li}^{+}\right)$is a monovalent cation, but because it is strongly hydrated it acquires an ionic diameter equivalent to that of magnesium $\left(\mathrm{Mg}^{2+}\right)$. Therefore, it primarily interferes with the binding of this key co-factor at specific metal ion binding sites and disrupts the function of a number of essential proteins. For example, lithium inhibits inositol monophosphatase (IMPase), glycogen synthase kinase 3 (GSK-3) and phosphoglucomutase (FGM). Its competition with $\mathrm{Mg}^{2+}$ also impacts $\mathrm{AC}$ and phosphomonoesterases such as inositol polyphosphate-1-phosphatase and fructose 1,6-bisphosphatase (FBPase $^{[9]}$. With the exception of the latter and FGM, which subserve glucose and glycogen metabolism, respectively, the majority of enzymes that are lithium sensitive are pivotal to cellular signal transduction pathways (see Table 1 and Fig. 3 for further detail).

Table 1. The actions of lithium on second messenger systems

\begin{tabular}{|l|l|l|l|}
\hline $\mathrm{Li}^{+}$target & Role in cellular signalling & Change in BD & Action of $\mathrm{Li}^{+}$ \\
\hline $\begin{array}{l}\text { AC and } \\
\text { cAMP }\end{array}$ & $\begin{array}{l}\text { AC and cAMP are activated } \\
\text { by monoaminergic } \\
\text { transmission. This stimulates } \\
\text { second messengers that } \\
\text { consequently regulate } \\
\text { neurotransmission }\end{array}$ & $\begin{array}{l}\text { Sensitivity of the system } \\
\text { is altered resulting in } \\
\text { modulation of excitatory } \\
\text { neurotransmission }\end{array}$ & $\begin{array}{l}\text { Modulation of } \\
\text { neurotransmission, by increasing } \\
\text { basal levels of AC and cAMP } \\
\text { such that large fluctuations that } \\
\text { normally occur in response to } \\
\text { monoaminergic stimulation are } \\
\text { minimized }\end{array}$ \\
\hline SMIT 126, 130]
\end{tabular}




\begin{tabular}{|c|c|c|c|}
\hline & & & $138,144]$ \\
\hline MARCKS & $\begin{array}{l}\text { Downstream target of PKC } \\
\text { that is responsible for release } \\
\text { of neurotransmitters }{ }^{[132]}\end{array}$ & $\uparrow$ in mania ${ }^{[146,148]}$ & $\begin{array}{l}\text { Inhibits MARCKS directly }{ }^{[148]} \\
\text { and indirectly via its action on } \\
\text { PKC }^{[132,138,147]}\end{array}$ \\
\hline $\begin{array}{l}\text { BDNF and } \\
\text { Bcl-2 }\end{array}$ & $\begin{array}{l}\text { Neuroprotective proteins that } \\
\text { are activated by CREB, } \\
\text { which is a downstream target } \\
\text { of } \mathrm{AC} \text { and } \mathrm{CAMP}{ }^{[9]}\end{array}$ & $\downarrow$ in $\mathrm{BD}^{[181,188]}$ & $\begin{array}{l}\text { Increases BDNF } \\
2^{[182]} \text { and Bcl- } \\
\text { of CREB activation through the } \\
\text { actions of lithium on cAMP }\end{array}$ \\
\hline GSK-3 & $\begin{array}{l}\text { Regulation of glycogen } \\
\text { synthesis, gene transcription, } \\
\text { synaptic plasticity and cell } \\
\text { structure and resilience }{ }^{[131,} \\
\text { 132] }\end{array}$ & Dysregulation $^{[192] a}$ & $\begin{array}{l}\text { Inhibits GSK directly, }{ }^{[193]} \text { which } \\
\text { then activates the Akt } \\
\text { neuroprotective pathway }{ }^{[195]}\end{array}$ \\
\hline
\end{tabular}

$A C$ adenyl cyclase, $B c l$-2 B-cell lymphoma 2, $B D$ bipolar disorder, $B D I$ bipolar 1 disorder, $B D N F$ brain-derived neurotrophic factor, $c A M P$ cyclic adenosine monophosphate, $C R E B$ cAMP response element binding transcription factor, DAG diaglycerol, GSK-3 glycogen synthase kinase 3, IP inositol phosphate, IPPase inositol phosphate 1phosphatase, IMPase inositol monophosphate 1-phosphatase, $I P_{3}$ inositol triphosphate, $\mathrm{Li}^{+}$lithium, MARCKS myristoylated alanine-rich c kinase substrate, $m I$ myo-inositol, $P I$ phospohinositide, $P I P_{2}$ phosphoinositol 4-5biphosphate, $P K C$ protein kinase C, PLC phospholipase C, SMIT sodium myo-inositol transporter; $\uparrow$ indicates increased, $\downarrow$ indicates decreased

a The exact role of GSK in the pathology of BD is not well understood, but given the actions of lithium on GSK it is postulated that GSK is dysregulated in BD 


\subsubsection{The Adenyl Cyclase and Cyclic Adenosine Monophosphate (cAMP) System}

The AC system is an important receptor-coupled second messenger system that is activated by monoaminergic neurotransmission ${ }^{[125]}$. AC is coupled to membrane-bound G-proteins that can stimulate $\left(G_{s}\right)$ or inhibit $\left(G_{i}\right)$ the production of cAMP ${ }^{[9]}$. The latter activates the enzyme, protein kinase A (PKA), which in turn regulates and phosphorylates ion channels, cytoskeletal structures and transcription factors such as cAMP response element binding protein (CREB). CREB is of particular interest because of its effects on brain-derived neurotrophic factor (BDNF) and B-cell lymphoma-2 (bcl-2) genes that are thought to play a key role in neuronal plasticity (see discussion in Sect 6.2.2 and Sect 6.2.3) ${ }^{[9]}$.

At concentrations of $2 \mathrm{mmol} / \mathrm{L}$, lithium balances AC system transduction by both enhancing basal activity while concurrently inhibiting stimulated activity. Therefore, acutely, lithium increases basal levels of AC and cAMP, partly by inhibiting the $\mathrm{G}_{\mathrm{i}}$ protein $^{[102,126,127]}$ (see Sect. 5.1). At the same time, when cells undergo stimulation, lithium minimizes the resultant fluctuations in cAMP by reducing $\mathrm{G}_{\mathrm{s}}$ activity and thereby conferring stability to the signalling system ${ }^{[110,125-129]}$. These acute effects eventually give way to long-term changes that are a consequence of prolonged lithium exposure in which cAMP and AC levels are further modified through gene transcription ${ }^{[9,126,130]}$.

\subsubsection{The Phosophoinositide Cycle}

Phosophoinositides (PIs) are the precursors for many signalling molecules that are important in receptormediated signal transduction pathways, and invoke a number of CNS responses ${ }^{[131-133]}$. Activation of a PI cycle-associated membrane receptor stimulates phospholipase C (PLC)-mediated hydrolysis of phosphoinositol-4-5-bisphosphate ( $\left.\mathrm{PIP}_{2}\right)$ into inositol triphosphate $\left(\mathrm{IP}_{3}\right)$ and DAG (see Fig. 3). The resulting products, $\mathrm{IP}_{3}$ and DAG, initiate $\mathrm{PKC}$ activation and the release of intracellular calcium, respectively ${ }^{[134]} \mathrm{IP}_{3}$ is then successively phosphorylated via the enzymes inositol phosphate 1phosphatase (IPPase) and ImPase ${ }^{[125]}$ to replenish myo-inositol (mI), which is then used to synthesize PIs. 
Additionally, extracellular inositol can enter the cell via a high-affinity sodium mI transport (SMIT) system, which also regulates mI levels ${ }^{[134]}$. In bipolar I disorder, studies suggest that the SMIT system is upregulated $^{[135]}$, and that disruption of the PI cycle by lithium affects the homeostasis of intracellular calcium $^{[133,136,137]}$.

One of the most widely discussed hypotheses regarding the action of lithium is the 'mI depletion hypothesis $^{,[116,133]}$. This postulates that lithium-induced inhibition of ImPase and IPPase depletes cellular $\mathrm{mI}$ and that this compromises the production of $\mathrm{PI}^{[102,117,138]}$. In addition, lithium inhibits the expression and activity of the SMIT system, thus limiting the entry of inositol into the cell and produces further depletion $^{[135]}$. Interestingly, the effects of lithium on SMIT take approximately 8 days, which is similar to the time lithium takes to exert its therapeutic effects clinically ${ }^{[134]}$. Together these changes compromise the synthesis of PI-dependent second messenger molecules ${ }^{[102,117]}$.

Studies on animals and animal models of mood disorders, as well as investigations of neural cell cultures and brain slices, have produced inconclusive evidence in relation to the $\mathrm{mI}$ depletion hypothesis. Clinical imaging studies using proton magnetic resonance spectroscopy (MRS) have also yielded equivocal findings. For instance, frontal lobe $\mathrm{mI}$ levels have been found to be increased during mania and depression, but remain comparable to healthy controls during euthymia, when mood is presumably stabilized with lithium ${ }^{[131,139,140]}$. Further, significant reductions in brain $\mathrm{mI}$ levels following acute lithium administration have been shown to correlate with an improvement in manic symptoms in children ${ }^{[141]}$. Interestingly, mI and IPPase levels are unaffected by lithium in euthymic patients supporting its role as an uncompetitive inhibitor. That is, lithium only inhibits the enzyme when it is in excess ${ }^{[131,139]}$. However, not all studies have found evidence to support the $\mathrm{mI}$ depletion hypothesis, and in a number of studies changes in mI following lithium administration correlates poorly with changes in clinical state ${ }^{[142]}$. Of 
note, several evaluations of the research in this field suggest that the therapeutic actions of lithium are probably not solely related to inositol but rather its downstream targets ${ }^{[133,140,142,143]}$.

\subsubsection{Protein Kinase C and Myristoylated Alanine-Rich C Kinase Substrate (MARCKS)}

$\mathrm{PKC}$ is an enzyme that is ubiquitous in the brain. It plays an important role in pre- and post-synaptic neurotransmission. PKC is activated by neurotransmitters through the PI cycle and phosphorylates its downstream target MARCKS, which is responsible for neuronal excitability and changes in gene expression and cell plasticity ${ }^{[131,132,138,140,144]}$. Increased platelet PKC activity has been found during periods of intense neurotransmission such as mania, further, post-mortem studies have shown increased levels of PKC in the prefrontal cortex of bipolar disorder patients compared with age-matched controls $^{[145]}$. Such elevated levels of PKC may hinder neuronal functioning ${ }^{[144,146]}$.

Acute treatment with lithium has been shown to activate PKC but over longer periods of time lithium tends to downregulate the activity of this kinase ${ }^{[147]}$ and its substrate MARCKS in the hippocampus ${ }^{[148]}$. It has been postulated on the basis of these studies in both animals and humans that the inhibition of PKC activity by lithium is related to its anti-manic effects ${ }^{[7]}$. For instance, elevated cystosolic and membraneassociated PKC activity in the platelets of manic patients, has been found to be significantly diminished after 2 weeks of lithium therapy at therapeutic concentrations ${ }^{[149]}$. In addition, animal models of mania have shown a reduction in PKC and MARCKS in the prefrontal cortex after 4 weeks of lithium treatment ${ }^{[146]}$. However, the precise role of PKC in the regulation of mood and the pathophysiology of bipolar disorder is not known.

\subsubsection{Intracellular Calcium}

Calcium is a highly diverse cation that plays multiple important roles in cellular functioning, from the regulation of neurotransmission to cellular integrity, metabolism and gene transcription ${ }^{[150,151]}$. When the cell is stimulated via the binding of a neurotransmitter to receptors at the cell surface, calcium enters the 
cell through channels on the cell membrane as well as via $\mathrm{IP}_{3}$-mediated release from the endoplasmic reticulum. This results in an increase of intracellular calcium levels that then propagates the cellular signal. When stimulation is ceased, calcium levels are restored via multiple sophisticated intracellular mechanisms ${ }^{[150]}$. Maintenance of calcium homeostasis is critical for efficiency of cellular signalling as well as cellular integrity ${ }^{[152]}$. Dysregulation of intracellular calcium is extensively documented in bipolar disorder. The most consistent finding is elevation of intracellular calcium levels, encompassing both basal and receptor-regulated calcium ${ }^{[153,154]}$. This may be a marker of illness state rather than a trait marker ${ }^{[155]}$.

Lithium has documented effects on intracellular calcium signalling. Lithium blocks the uptake of calcium into cells in both individuals with bipolar disorder and controls ${ }^{[156]}$. Specifically, lithium attenuates calcium influx after activation of the NMDA receptor. Following activation of both metabotropic glutamate receptors (mGluR) 1/5, lithium attenuates calcium release, and was linked to downregulation of the plasma membrane expression of the mGluR5 receptor. Lithium decreases intracellular calcium levels and intracellular calcium stores ${ }^{[157]}$. Curiously, valproate, but not lamotrigine share the ability of lithium to attenuate the lysophosphatidic acid-stimulated calcium responses in B lymphoblast cell lines from bipolar I disorder patients ${ }^{[158]}$. Lithium blocks excitotoxic processes, at least in part via calcium. Lithium blocks the excitotoxic process induced by kainate via modulation of calcium entry and the consequent inhibition of the calpain pathway ${ }^{[159]}$. Calpain is a protease that has a role in apoptotic pathways, and is activated by intracellular calcium ${ }^{[160]}$.

\subsection{Neuroprotective Pathways}

As previously mentioned, bipolar disorder is increasingly recognized as a degenerative disease for which lithium has been shown to be neuroprotective. There are several models and hypotheses that have been posited to explain how degenerative changes lead to bipolar disorder. One such theory is the 'neurosensitization model' in which manic/depressed episodes cause changes in gene expression, which 
in turn permanently alter neuronal activity. This transformation renders key neuronal networks dysfunctional such that the individual becomes more susceptible to relapse and less likely to respond to medication ${ }^{[8]}$. An alternate model, the 'allostatic load hypothesis', proposes that 'wear and tear' caused by episodes of mania and depression, alters the functioning of key brain circuits that eventually lead to cognitive decline, and increase the likelihood of further illness and resistance to treatment ${ }^{[8]}$. A third hypothesis is the 'neurodevelopmental model', which simply suggests that a decrease in cell density in the bipolar brain is the product of abnormal neural development. Interestingly, this pattern of atrophy has been found not only in adults with bipolar disorder but also in paediatric patients ${ }^{[161]}$, and nonsymptomatic family members of bipolar disorder patients ${ }^{[162]}$, suggesting that this is a process that commences early in life. More recently, the 'neuroprogression model' posits that the disorder has a progressive course, mediated by factors including inflammation, oxidative stress, neurotrophins, mitochondrial dysfunction and apoptosis ${ }^{[8,12]}$.

Lithium has demonstrated neuroprotective effects by both preventing apoptosis and promoting cellular longevity ${ }^{[8,10]}$. When cells are exposed to an insult such as excessive glutamate excitation, certain kinases are activated through phosphorylation, specifically c-Jun N-terminal kinase and p38 mitogen-activated $\operatorname{protein}^{[163,164]}$. Together these kinases increase binding of the DNA transcription factor, activator protein1, and this in turn activates apoptosis. Excess glutamate therefore increases levels of pro-apoptotic proteins, such as p53 and Bax, while at the same time downregulating cytoprotective proteins such as bcl2. Thus, cell atrophy in bipolar disorder is thought to occur not only because of the toxic consequences of recurrent affective episodes, but also the "endogenous impairment of "cellular resiliency",[7, 162]. Hence, chronic treatment of bipolar disorder with lithium both modulates enzymatic apoptosis pathways and increases the availability of neuroprotective factors ${ }^{[126,165,166]}$.

\subsubsection{Oxidative Metabolism}


There has been growing evidence that points towards mitochondrial dysfunction playing a role in the pathophysiology of bipolar disorder. As well as being the energy centre of the cell, mitochondria play a central role in mediating apoptosis and regulating intracellular calcium, both of which have implications

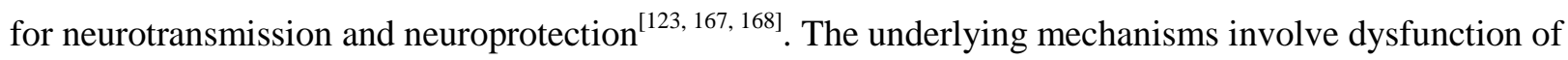
endoplasmic reticulum and mitochondrial calcium homeostasis ${ }^{[169]}$, and polymorphisms of the bcl-2 protein contribute to this dysregulation. Mitochondrial dysfunction is present in bipolar disorder, including decreased activity of complex 1 of the mitochondrial electron transport chain ${ }^{[170]}$. Lithium upregulates complexes I and $\mathrm{II}^{[171]}$. Glutathione plays a key role in the interaction between lithium, mitochondrial dysfunction and oxidative stress ${ }^{[172,173]}$.

Oxidative stress occurs when anti-oxidants are no longer able to remove excessive by-products of energy metabolism such as free radicals. These by-products are toxic and cause cellular damage and may induce inflammation and activate apoptosis pathways ${ }^{[167]}$. Oxidative stress is particularly pronounced during periods of mania and results in cell damage that is cumulative over time, such that with recurrent episodes the likelihood of a clinical response to treatment gradually diminishes ${ }^{[174,175]}$.

In addition to an increase in oxidative processes ${ }^{[176]}$, patients with bipolar disorder have reduced levels of anti-oxidants (such as glutathione) and associated enzymes ${ }^{[177]}$. Further, N-acetyl aspartate, a marker of mitochondrial function and neuroprotection, is reduced in bipolar disorder patients ${ }^{[123,178]}$; however, lithium is thought to stimulate mitochondrial respiratory chain complexes, in a dose-dependent manner ${ }^{[171]}$, and in doing so is perhaps able to protect against oxidative stress ${ }^{[179]}$. In keeping with this, compared with patients treated with lithium during acute mania, unmedicated bipolar disorder patients have higher markers of lipid peroxidation, and levels of oxidative enzymes are increased, to possibly compensate for increased levels of stress ${ }^{[180]}$. 


\subsubsection{Brain-Derived Neurotrophic Factor (BDNF)}

BDNF is an important neuroprotective protein that has been shown to be decreased in both the manic and depressed phases of bipolar disorder ${ }^{[181]}$, but increased in patients effectively treated with lithium in combination with other medications for mania. ${ }^{[182]}$ This increase in BDNF expression with lithium treatment has been postulated to provide protection against glutamate-induced excitotoxicty ${ }^{[111]}$. Interestingly, BDNF levels have been shown to increase about 5 days after lithium administration in animals ${ }^{[111]}$. Clinically, lithium takes 6-10 days to achieve an anti-manic effect and some researchers have suggested that this delay is the time required for BDNF to regenerate to neuroprotective levels ${ }^{[183]}$.

Interestingly, a recent study compared lithium responders with non-responders with respect to cognition and plasma BDNF levels. This study found that compared with healthy controls, lithium responders performed similarly on cognitive function tests and had no difference in BDNF levels. However, nonresponders performed worse on cognitive tests and had lower levels of BDNF than both lithium responders and healthy controls. This study suggests that the neuroprotective role of lithium is related to facilitatory effects on $\mathrm{BDNF}^{[184]}$. Lithium impacts other growth factors such as epidermal growth factor and insulin growth factor, although these pathways are less well explored than $\mathrm{BDNF}^{[185,186]}$.

\subsubsection{B-Cell Lymphoma 2 (Bcl-2)}

Bcl-2 is a neuroprotective protein that regulates cellular apoptotic pathways and has been implicated in neurotrophy ${ }^{[187]}$. As such, a decrease in bcl-2 is thought to contribute to mania ${ }^{[188]}$. Of note, chronic lithium therapy increases both bcl-2 messenger RNA (mRNA) ${ }^{[166]}$ and bcl-2 levels ${ }^{[187-189]}$ and reduces $\operatorname{apoptosis}^{[190]}$.

\subsubsection{Glycogen Synthase Kinase 3 (GSK-3)}

GSK-3 is an enzyme responsible for regulating glycogen synthesis. It has direct involvement in gene transcription, synaptic plasticity, cell structure and resilience ${ }^{[8,131,132]}$. Further, it is a down-stream target 
of monoaminergic systems and growth factor cascades, and therefore is implicated in the regulation of $\operatorname{mood}^{[183]}$. GSK-3 is activated under conditions of chronic stress, such as prolonged exposure to dopamine during mania ${ }^{[191]}$, and has been shown to cause hyperactivity in mice ${ }^{[192]}$. Lithium directly inhibits GSK$3^{[193]}$ by regulating serine 9-phosphorylation $3^{[194]}$ and the inhibition of GSK also activates the Akt neuroprotective pathway ${ }^{[165,195]}$.

This effect on GSK-3 may therefore be key to its therapeutic properties ${ }^{[131,132,196]}$, and though GSK inhibition does not reliably produce an antidepressant effect in murine models of depression ${ }^{[197]}$, many studies have demonstrated antidepressant-like effects ${ }^{[198]}$. Specifically, lithium has been shown to increase synaptic plasticity and decrease GSK expression that has been induced in murine models of depression $^{[199]}$. These conflicting findings reflect the comparatively poorer efficacy of lithium in treating the depressive phase of bipolar disorder as compared with mania ${ }^{[200]}$.

\subsubsection{Autophagy}

Autophagy is an important physiological process that cells use to regulate neuronal viability and function. It occurs in response to cellular stress and is responsible for degradation of intracellular proteins, and hence its main role involves the recycling of these proteins and nutrients ${ }^{[201,202]}$. The mammalian target of rapamycin (mTOR) is a negative regulator of the autophagy process. GSK-3 inhibition activates mTOR and therefore decreases autophagy ${ }^{[203]}$. However, ImPase inhibition via lithium (see section 6.1.2), decreases $\mathrm{IP}_{3}$ levels, which in turn induces autophagy ${ }^{[204]}$. Hence, lithium both inhibits and induces autophagy by its effects in reducing GSK-3 and ImPase, respectively ${ }^{[204,205]}$. While its role in the inhibition of autophagy has been considered important in explaining the neuroprotective properties of lithium, it is still not well understood.

\subsection{Summary}


Lithium acts on a number of molecules within second messenger systems that possibly underpin its regulatory effects on neurotransmission and its neuroprotective properties. It modulates neurotransmission by moderating AC and cAMP fluctuations and by limiting mI, PKC and MARCKS. Over time these constraints modify gene transcription within the cell and yield long-lasting mood stabilization.

At the same time, lithium is able to reduce the oxidative burden caused by episodes of illness and protect against apoptosis by promoting neuroprotective pathways such as Akt and facilitating the actions of neuroprotective proteins such as BDNF and bcl-2. It also inhibits pro-apoptotic proteins such as p53 and processes such as autophagy. These neuroprotective properties are increasingly recognized as an important quality of lithium for the treatment of bipolar disorder and other neurodegenerative $\operatorname{disorders}^{[206]}$.

\section{Conclusion}

It is clear that lithium possesses a complex set of actions involving neurotransmission and cellular signalling pathways that translate to its many clinical effects involving mood and cognition. Interestingly, its therapeutic and neuroprotective effects are most pronounced in the presence of pathology. For example, as described earlier, in studies of cognition in non-psychiatric populations the effects of lithium appear to be detrimental, but in bipolar disorder patients its long-term effects are beneficial. Similarly, when because of mania the levels of neurotransmitters such as glutamate or dopamine increase dramatically, lithium is able to counteract these changes and stabilize neurotransmission whereas in the absence of pathology it increases basal levels of these excitatory substances. This selectivity of action is also evident at a cellular level. For example, inositol is depleted by lithium in certain brain regions but only when the levels are significantly raised as found in mania or depression. 
While these findings are remarkable, there remain several important considerations that limit our understanding of the mechanism of action of lithium. First, the pathophysiology of bipolar disorder is likely to be complex and will be complicated further by the effects of lithium. Therefore, the compensatory changes that accompany treatment may be difficult to disentangle from any primary dysfunction. Second, neurotransmission is in itself a highly sophisticated process that involves multiple interconnected pathways. Hence, identifying common targets across the various phases of bipolar disorder is inherently difficult and requires examination of patients in each of the various mood states. Third, a significant proportion of the findings that have contributed to our understanding of lithium derive from in vitro studies, and preclinical in vivo studies. Many of these studies use lithium concentrations that are higher than those that are used therapeutically, and while it could be speculated that different concentrations of lithium may have very different neurobiological effects that may underlie some of the different clinical effects of lithium, these studies are not easily translated for application in human studies especially as appropriate animal models of bipolar disorder have not yet been established.

It is therefore important to note that the potential mechanisms of action of lithium that have been detailed in this paper are tentative and that there are many aspects that require replication and further research. Most pressing perhaps is the need for longitudinal studies to determine whether the mood-stabilizing and neuroprotective properties of lithium share a common mechanism and how the two effects are interrelated, if at all. In addition, studies need to utilize multi-modal approaches that employ the latest advances in technology within fields such as neuroimaging and genetics alongside careful selection of patients with bipolar disorder.

By integrating basic sciences research and clinical studies it is hoped that a more complete picture of the actions of this enigmatic element will emerge and that it may also provide insights into the 
pathophysiology of bipolar disorder. Indeed, it has been argued that most of the primary insights into the pathophysiology of psychiatric disorders are derived from reverse engineering the properties of effective therapies. This remains the primary road forward in bipolar disorder ${ }^{[207]}$.

\section{Acknowledgements}

Gin S. Malhi has received research support from AstraZeneca, Eli Lilly, Organon, Pfizer, Servier and Wyeth; has been a speaker for AstraZeneca, Eli Lilly, Janssen-Cilag, Lundbeck, Pfizer, Ranbaxy, Servier, and Wyeth; and has been a consultant for AstraZeneca, Eli Lilly, Janssen-Cilag, Lundbeck and Servier. Michael Berk has received research support from the Medical Benefits Fund of Australia, Bristol-Myers Squibb, Eli Lilly, GlaxoSmithKline, Organon, Novartis, Mayne Pharma and Servier; has been a speaker for AstraZeneca, Bristol-Myers Squibb, Eli Lilly, GlaxoSmithKline, Janssen-Cilag, Lundbeck, Merck, Pfizer, Sanofi-Synthelabo, Servier, Solvay and Wyeth; and has served as a consultant to AstraZeneca, Bristol-Myers Squibb, Eli Lilly, GlaxoSmithKline, Janssen-Cilag, Lundbeck and Servier. Michelle Tanious, Pritha Das and Carissa Coulston have no conflicts of interests or funding to declare. This work was supported by a National Health and Medical Research Council program grant (510135).

\section{REFERENCES}

1. Malhi GS, Gershon S. Ion men and thier mettle. Aust N Z J Psychiatry 2009;43:1091-5.

2. Grunze H, Vieta E, Goodwin GM, et al. The World Federation of Societies of Biological Psychiatry (WFSBP) guidelines for the biological treatment of bipolar disorders: update 2009 on the treatment of acute mania. World J Biol Psychiatry 2009;10(2):85-116.

3. Baldessarini RJ, Tondo L, Davis P, et al. Decreased risk of suicides and attempts during longterm lithium treatment: a meta-analytic review [see comment]. [erratum appears in Bipolar Disord 2007 May;9(3):314]. Bipolar Disord 2006 Oct;8(5 Pt 2):625-39.

4. Malhi GS, Adams D, Berk M. Is lithium in a class of its own? A brief profile of its clinical use. Aust N Z J Psychiatry 2009 Dec;43:1093-104.

5. Goodwin FK, Fireman B, Simon GE, et al. Suicide risk in bipolar disorder during treatment with lithium and divalproex. JAMA 2003 Sep 17;290(11):1467-73. 
6. Bowden CL. Bipolar pathophysiology and development of improved treatments. Brain Res 2008 Oct;1235:92-7.

7. Manji HK, Chen G. PKC, MAP kinases and the bcl-2 family of proteins as long-term targets for mood stabilizers. Mol Psychiatry 2002;7 Suppl. 1:S46-56.

8. Berk M. Neuroprogression: pathways to progressive brain changes in bipolar disorder. Int J Neuropsychopharmacol 2009 May;12(4):441-5.

9. Quiroz JA, Machado-Vieira R, Zarate JCA, et al. Novel insights into lithium's mechanism of action: neurotrophic and neuroprotective effects. Neuropsychobiology 2010;62(1):50-60.

10. Post RM, Speer AM, Hough CJ, et al. Neurobiology of bipolar illness: implications for future study and therapeutics. Ann Clin Psychiatry 2003 Jun;15(2):85-94.

11. Chen G, Rajkowska G, Du F, et al. Enhancement of hippocampal neurogenesis by lithium. J Neurochem 2000;75(4):1729-34.

12. Berk M, Kapczinski F, Andreazza AC, et al. Pathways underlying neuroprogression in bipolar disorder: focus on inflammation, oxidative stress and neurotrophic factors. Neuroscience Biobehav Rev 2011;35(3):804-17.

13. Baldessarini RJ, Tondo L. Does lithium treatment still work? Evidence of stable responses over three decades. Arch Gen Psychiatry 20000;57(2):187-90.

14. Bowden CL, Mosolov S, Hranov L, et al. Efficacy of valproate versus lithium in mania or mixed mania: a randomized, open 12-week trial. Int Clin Psychopharmacol 2010 Mar;25(2):60-7.

15. Yildiz A, Vieta E, Leucht S, et al. Efficacy of antimanic treatments: meta-analysis of randomized, controlled trials. Neuropsychopharmacology 2011;36(2):375-89. 
16. Shafti SS. Olanzapine vs. lithium in management of acute mania. J Affect Disord 2010;122(3):273-6.

17. Segal J, Berk M, Brook S. Risperidone compared with both lithium and haloperidol in mania: a double-blind randomized controlled trial. Clin Neuropharmacol 1998;21(3):176-80.

18. Gershon S, Chengappa KR, Malhi GS. Lithium specificity in bipolar illness: a classic agent for a classic disorder. Bipolar Disord 2009;11 Suppl. 2:34-44.

19. Geddes JR, Burgess S, Hawton K, et al. Long-term lithium therapy for bipolar disorder: systematic review and meta-analysis of randomized controlled trials. Am J Psychiatry 2004 Feb;161(2):217-22.

20. Cipriani A, Barbui C, Salanti G, et al. Comparative efficacy and acceptability of antimanic drugs in acute mania: a multiple-treatments meta-analysis. The Lancet 2011 Oct 8;378(9799):1306-15.

21. Berk M, Malhi GS. Should antipsychotics take pole position in mania treatment? The Lancet 2011;378(9799):1279-81.

22. National Institute for Health and Clincial Excellence. Bipolar disorder: the management of bipolar disorder in adults, children and adolescents, in primary and secondary care: clinical guideline 38. London: National Institute for Health and Clincial Excellence, 2006.

23. Yatham LN, Kennedy SH, O'Donovan C, et al. Canadian Network for Mood and Anxiety Treatments (CANMAT) guidelines for the management of patients with bipolar disorder: consensus and controversies. Bipolar Disord 2005 Jun;7(Suppl.3):5-69.

24. Yatham LN, Kennedy SH, O'Donovan C, et al. Canadian Network for Mood and Anxiety Treatments (CANMAT) guidelines for the management of patients with bipolar disorder: update 2007. Bipolar Disord 2006 Dec;8(6):721-39. 
25. Malhi GS, Adams DA, Lampe L, et al. Clinical practice recommendations for bipolar disorder. Acta Psychiatr Scand 2009;119(Suppl. 439):27-46.

26. Tohen M, Chengappa KN, Suppes T, et al. Efficacy of olanzapine in combination with valproate or lithium in the treatment of mania in patients partially nonresponsive to valproate or lithium monotherapy. Arch Gen Psychiatry 2002 Jan 1;59(1):62-9.

27. Bhagwagar Z, Goodwin GM. The role of lithium in the treatment of bipolar depression. Clin Neurosci Res 2002;2(3-4):222-7.

28. Van Lieshout RJ, MacQueen GM. Efficacy and acceptability of mood stabilisers in the treatment of acute bipolar depression: systematic review. Br J Psychiatry 2010 Apr;196(4):266-73.

29. Fountoulakis KN. An update of evidence-based treatment of bipolar depression: where do we stand? Curr Opin Psychiatry 2010;23(1):19-24.

30. Fountoulakis KN, Grunze H, Panagiotidis P, et al. Treatment of bipolar depression: an update. J Affect Disord 2008;109(1-2):21-34.

31. Vieta E, Locklear J, Gunther O, et al. Treatment options for bipolar depression: a systematic review of randomized, controlled trials. J Clin Pyschopharmacol 2010;30:579-90.

32. Grandjean EM, Aubry JM. Lithium: updated human knowledge using an evidence-based approach. Part I: clinical efficacy in bipolar disorder. CNS Drugs 2009;23(3):225-40.

33. Yatham LN, Kennedy SH, Schaffer A, et al. Canadian Network for Mood and Anxiety Treatments (CANMAT) and International Society for Bipolar Disorders (ISBD) collaborative update of CANMAT guidelines for the management of patients with bipolar disorder: update 2009. Bipolar Disord 2009 May;11(3):225-55. 
34. Young AH, Hammond JM. Lithium in mood disorders: increasing evidence base, declining use? Br J Psychiatry 2007;191:474-6.

35. Coryell W. Maintenance treatment in bipolar disorder: a reassessment of lithium as the first choice. Bipolar Disord 2009;11:77-83.

36. Geddes JR, Goodwin GM, Rendell J, et al. Lithium plus valproate combination therapy versus monotherapy for relapse prevention in bipolar I disorder (BALANCE): a randomised open-label trial. Lancet 2010 Jan 30;375(9712):385-95.

37. Silverstone T. Is lithium still the maintenance treatment of choice for bipolar disorder? CNS Drugs 2000 Aug;14(2):81-94.

38. Perlis R, Sachs G, Lafer B, et al. Effect of abrupt change from standard to low serum levels of lithium: a reanalysis of double-blind lithium maintenance data. Am J Psychiatry 2002;159(7):1155-9.

39. Cavanagh J, Smyth R, Goodwin GM. Relapse into mania or depression following lithium discontinuation: a 7-year follow-up. Acta Psychiatr Scand 2004;109(2):91-5.

40. Klein E, Lavie P, Meiraz R, et al. Increased motor activity and recurrent manic episodes: predictors of rapid relapse in remitted bipolar disorder patients after lithium discontinuation. Biol Psychiatry 1992;31(3):279-84.

41. Bowden C, Gögüs A, Grunze H, et al. A 12-week, open, randomized trial comparing sodium valproate to lithium in patients with bipolar I disorder suffering from a manic episode. Int Clin Psychopharmacol 2008;23(5):254-62.

42. Malhi GS, Adams D, Cahill CM, et al. The management of individuals with bipolar disorder: a review of the evidence and its integration into clinical practice. Drugs 2009;69(15):2063-101. 
43. Bowden CL. The ability of lithium and other mood stabilisers to decrease suicide risk and prevent relapse. Curr Psychiatric Rep 2000;2:490-4.

44. Muller-Oerlinghausen B. Arguments for the specificity of the antisuicidal effect of lithium. Eur Arch Psychiatry Clin Neurosci 2001;251(Suppl. 2):II/72-II/5.

45. Cipriani A, Pretty H, Hawton K, et al. Lithium in the prevention of suicidal behavior and allcause mortality in patients with mood disorders: a systematic review of randomized trials [see comment]. Am J Psychiatry 2005 Oct;162(10):1805-19.

46. Wingo AP, Wingo TS, Harvey PD, et al. Effects of lithium on cognitive performance: a metaanalysis. J Clin Psychiatry 2009;70(11):1588-97.

47. Engelsmann F, Katz J, Ghadirian AM, et al. Lithium and memory: a long term follow-up study. J Clin Psychopharmacol 1988;8(3):207-12.

48. Smigan L, Perris C. Memory functions and prophylactic lithium treatment. Psychol Med 1983;13:529-36.

49. Pachet AK, Wisniewski AM. The effects of lithium on cognition: an updated review. Psychopharmacology (Berl) 2003;170:225-34.

50. Kessing LV, Forman JL, Andersen PK. Does lithium protect against dementia? Bipolar Disord 2010;12(1):87-94.

51. Arts B, Jabben N, Krabbendam L, et al. A 2-year naturalistic study on cognitive functioning in bipolar disorder. Acta Psychiatr Scand 2011;123(3):190-205.

52. Rybakowski JK, Permoda-Osip A, Borkowska A. Response to prophylactic lithium in bipolar disorder may be associated with a preservation of executive cognitive functions. Eur Neuropsychopharmacol 2009 Nov;19(11):791-5. 
53. Anand A, Shekhar A. Brain imaging studies in mood and anxiety disorders. Ann N Y Acad Sci 2003;985(1):370-88.

54. Bell EC, Willson MC, Wilman AH, et al. Differential effects of chronic lithium and valproate on brain activation in healthy volunteers. Hum Psychopharmacol Clin Exp 2005;20(6):415-24.

55. Bell EC, Willson MC, Wilman AH, et al. Lithium and valproate attenuate dextroamphetamineinduced changes in brain activation. Hum Psychopharmacol 2005;20(2):87-96.

56. Silverstone PH, Bell EC, Willson MC, et al. Lithium alters brain activation in bipolar disorder in a task- and state-dependent manner: an fMRI study. Ann Gen Psychiatry 2005;4(14):1-7.

57. Tsaltas E, Kontis D, Boulougouris V, et al. Lithium and cognitive enhancement: leave it or take it? Psychopharmacology (Berl) 2009;202(1-3):457-76.

58. Emsell L, McDonald C. The structural neuroimaging of bipolar disorder. Int Rev Psychiatry 2009;21(4):297-313.

59. Kempton MJ, Geddes JR, Ettinger U, et al. Meta-analysis, database, and meta-regression of 98 structural imaging studies in bipolar disorder. Arch Gen Psychiatry 2008 Sep;65(9):1017-32.

60. Strakowski SM, DelBello MP, Adler CM. The functional neuroanatomy of bipolar disorder: a review of neuroimaging findings. Mol Psychiatry 2005;10:105-16.

61. Hajek T, Cullis J, Novak T, et al. Hippocampal volumes in bipolar disorders: opposing effects of illness burden and lithium treatment. Bipolar Disord 2012;14(3):261-70.

62. Chepenik LG, Wang F, Spencer L, et al. Structure-function associations in hippocampus in bipolar disorder. Biol Psychol 2012;90(1):18-22. 
63. Savitz J, Nugent AC, Bogers W, et al. Amygdala volume in depressed patients with bipolar disorder assessed using high resolution 3T MRI: the impact of medication. Neuroimage 2010;49(4):296676.

64. Foland-Ross LC, Brooks Iii JO, Mintz J, et al. Mood-state effects on amygdala volume in bipolar disorder. J Affect Disord 2012;139(3):298-301.

65. Hajek T, Gunde E, Slaney C, et al. Striatal volumes in affected and unaffected relatives of bipolar patients: high-risk study. J Psychiatr Res 2009;43(7):724-9.

66. DelBello MP, Zimmerman ME, Mills NP, et al. Magnetic resonance imaging analysis of amygdala and other subcortical brain regions in adolescents with bipolar disorder. Bipolar Disord $2004 ; 6(1): 43-52$.

67. Strakowski SM, DelBello MP, Zimmerman ME, et al. Ventricular and periventricular structural volumes in first- versus multiple-episode bipolar disorder. Am J Psychiatry 2002;159:1841-7.

68. Drevets WC, Price JL, Simpson JR, et al. Subgenual prefrontal cortex abnormalities in mood disorders. Nature 1997;386(6627):824-7.

69. Sassi RB, Brambilla P, Hatch JP, et al. Reduced left anterior cingulate volumes in untreated bipolar patients. Biol Psychiatry 2004 Oct 1;56(7):467-75.

70. López-Larson MP, DelBello MP, Zimmerman ME, et al. Regional prefrontal gray and white matter abnormalities in bipolar disorder. Biol Psychiatry 2002;52(2):93-100.

71. Brooks 3rd JO, Bonner JC, Rosen AC, et al. Dorsolateral and dorsomedial prefrontal gray matter density changes associated with bipolar depression. Psychiatry Res 2009 Jun 30;172(3):200-4.

72. Rajkowska G. Cell pathology in bipolar disorder. Bipolar Disord 2002;4(2):105-16. 
73. Rajkowska G, Halaris A, Selemon LD. Reductions in neuronal and glial density characterize the dorsolateral prefrontal cortex in bipolar disorder. Biol Psychiatry 2001;49(9):741-52.

74. Öngür D, Drevets WC, Price JL. Glial reduction in the subgenual prefrontal cortex in mood disorders. Proceedings of the National Academy of Sciences 1998 Oct 27;95(22):13290-5.

75. Brambilla P, Nicoletti MA, Harenski K, et al. Anatomical MRI study of subgenual prefrontal cortex in bipolar and unipolar subjects. Neuropsychopharmacology 2002;27(5):792-9.

76. Fornito A, Malhi GS, Lagopoulos J, et al. Anatomical abnormalities of the anterior cingulate and paracingulate cortex in patients with bipolar I disorder. Psychiatry Res Neuroimaging 2008;162(2):12332.

77. Brambilla P, Harenski K, Nicoletti M, et al. Differential effects of age on brain gray matter in bipolar patients and healthy individuals. Neuropsychobiology 2001;43(4):242-7.

78. Bearden CE, Thompson PM, Dalwani M, et al. Greater cortical gray matter density in lithiumtreated patients with bipolar disorder [see comment]. Biol Psychiatry 2007 Jul 1;62(1):7-16.

79. Sassi RB, Nicoletti M, Brambilla P, et al. Increased gray matter volume in lithium-treated bipolar disorder patients. Neurosci Lett 2002;329(2):243-5.

80. Adler CM, Levine AD, DelBello MP, et al. Changes in gray matter volume in patients with bipolar disorder. Biol Psychiatry 2005 Jul 15;58(2):151-7.

81. Takahashi T, Malhi GS, Wood SJ, et al. Gray matter reduction of the superior temporal gyrus in patients with established bipolar I disorder. J Affect Disord 2010;123:276-82.

82. Usher J, Menzel P, Schneider-Axmann T, et al. Increased right amygdala volume in lithiumtreated patients with bipolar I disorder. Acta Psychiatr Scand 2010;121:119-24. 
83. Foland LC, Altshuler LL, Sugar CA, et al. Increased volume of the amygdala and hippocampus in bipolar patients treated with lithium. Neuroreport 2008 Jan 22;19(2):221-4.

84. Hallahan B, Newell J, Soares JC, et al. Structural magnetic resonance imaging in bipolar disorder: an international collaborative mega-analysis of individual adult patient data. Biol Psychiatry 2011;69(4):326-35.

85. van Erp TGM, Thompson PM, Kieseppä T, et al. Hippocampal morphology in lithium and nonlithium-treated bipolar I disorder patients, non-bipolar co-twins, and control twins. Hum Brain Mapp 2012;33(3):501-10.

86. Yucel K, Taylor VH, McKinnon MC, et al. Bilateral hippocampal volume increase in patients with bipolar disorder and short-term lithium treatment. Neuropsychopharmacology 2008;33(2):361-7.

87. Moore GJ, Cortese BM, Glitz DA, et al. A longitudinal study of the effects of lithium treatment on prefrontal and subgenual prefrontal gray matter volume in treatment-responsive bipolar disorder patients. J Clin Psychiatry 2009 May;70(5):699-705.

88. Schildkraut JJ. The catecholamine hypothesis of affective-disorders: a review of supporting evidence. Am J Psychiatry 1965;122(5):509-22.

89. Pert A, Rosenblatt JE, Sivit C, et al. Long-term treatment with lithium prevents the development of dopamine receptor supersensitivity. Science 1978;201(4351):171-3.

90. Knapp S, Mandell AJ. Short- and long-term lithium administration: effects on the brain's serotonergic biosynthetic systems. Science 1973 May 11;180(4086):645-7.

91. Belmaker RH. Bipolar disorder. N Engl J Med 2004;351(5):476-86.

92. Berk M, Dodd S, Kauer-Sant'Anna M, et al. Dopamine dysregulation syndrome: implications for a dopamine hypothesis of bipolar disorder. Acta Psychiatr Scand 2007;116(Suppl. 434):41-9. 
93. Cousins DA, Butts K, Young AH. The role of dopamine in bipolar disoerder. Bipolar Disord 2010;11:787-806.

94. Jacobs D, Silverstone T. Dextroamphetamine-induced arousal in human subjects as a model for mania. Psychol Med 1986;16(02):323-9.

95. Post RM, Jimerson DC, Bunney WE, et al. Dopamine and mania: behavioral and biochemical effects of the dopamine receptor blocker pimozide. Psychopharmacology (Berl) 1980;67(3):297-305.

96. Staunton DA, Magistretti PJ, Shoemaker WJ, et al. Effects of chronic lithium treatment on dopamine receptors in the rat corpus striatum: I. Locomotor activity and behavioral supersensitivity. Brain Res 1982;232(2):391-400.

97. Gambarana C, Ghiglieri O, Masi F, et al. The effects of long-term administration of rubidium or lithium on reactivity to stress and on dopamine output in the nucleus accumbens in rats. Brain Res 1999;826(2):200-9.

98. Ichikawa J, Dai J, Meltzer HY. Lithium differs from anticonvulsant mood stabilizers in prefrontal cortical and accumbal dopamine release: role of 5-HT1A receptor antagonism. Brain Res 2005;1049:18290.

99. Ferrie L, Young AH, McQuade R. Effect of lithium and lithium withdrawal on potassium-evoked dopamine release and tyrosine hydroxylase expression in the rat. Int J Neuropsychopharmacol 2006 Dec;9(6):729-35.

100. Ferrie L, Young AH, McQuade R. Effect of chronic lithium and withdrawal from chronic lithium on presynaptic dopamine function in the rat. J Psychopharmacol (Oxf) 2005 May 1;19(3):229-34.

101. Malhi GS, Tanious M, Gershon S. The lithiumeter: a measured approach. Bipolar Disord 2011;13(3):219-26. 
102. Manji HK, Lenox RH. Signaling: cellular insights into the pathophysiology of bipolar disorder. Biol Psychiatry 2000 Sep 15;48(6):518-30.

103. Michael N, Erfurth A, Ohrmann P, et al. Acute mania is accompanied by elevated glutamate/glutamine levels within the left dorsolateral prefrontal cortex. Psychopharmacology (Berl) 2003;168(3):344-6.

104. Öngür D, Jensen JE, Prescot AP, et al. Abnormal glutamatergic neurotransmission and neuronalglial interactions in acute mania. Biol Psychiatry 2008;64(8):718-26.

105. Berk M. Lamotrigine and the treatment of mania in bipolar disorder. Eur Neuropsychopharmacol 1999;9 Suppl. 4:S119-S23.

106. Tsapakis EM, Travis MJ. Glutamate and psychiatric disorders. Advance Psychiatric Treat 2002;8:189-97.

107. Hokin LE, Dixon JF, Los GV. A novel action of lithium: stimulation of glutamate release and inositol 1,4,5 trisphosphate accumulation via activation of the $\mathrm{N}$-methyl $\mathrm{D}$-aspartate receptor in monkey and mouse cerebral cortex slices. Adv Enzyme Regul 1996;36:229-44.

108. Ghasemi M, Dehpour AR. The NMDA receptor/nitric oxide pathway: a target for the therapeutic and toxic effects of lithium. Trends Pharmacol Sci 2011;32(7):420-34.

109. Dixon JF, Hokin LE. Lithium acutely inhibits and chronically up-regulates and stabilizes glutamate uptake by presynaptic nerve endings in mouse cerebral cortex. Proc Natl Acad Sci U S A 1998 Jul 7;95(14):8363-8.

110. Brunello N, Tascedda F. Cellular mechanisms and second messengers: relevance to the psychopharmacology of bipolar disorders. Int J Neuropsychopharmacol 2003 Jun;6(2):181-9. 
111. Hashimoto R, Takei N, Shimazu K, et al. Lithium induces brain-derived neurotrophic factor and activates TrkB in rodent cortical neurons: an essential step for neuroprotection against glutamate excitotoxicity. Neuropharmacology 2002 Dec;43(7):1173-9.

112. Nonaka S, Hough CJ, Chuang D-M. Chronic lithium treatment robustly protects neurons in the central nervous system against excitotoxicity by inhibiting N-methyl-D-aspartate receptor-mediated calcium influx. Proc Natl Acad Sci U S A 1998 Mar 3;95(5):2642-7.

113. Bown CD, Wang JF, Young LT. Attenuation of N-methyl-D-aspartate-mediated cytoplasmic vacuolization in primary rat hippocampal neurons by mood stabilizers. Neuroscience 2003;117(4):949-55.

114. Ng WXD, Lau IY, Graham S, Sim K. Neurobiological evidence for thalamic, hippocampal and related glutamatergic abnormalities in bipolar disorder: a review and synthesis. Neurosci Biobehav Rev 2009 Mar;33(3):336-54.

115. Brambilla P, Perez J, Barale F, et al. GABAergic dysfunction in mood disorders. Mol Psychiatry 2003;8(8):721-37.

116. Kato T. Molecular neurobiology of bipolar disorder: a disease of 'mood-stabilizing neurons'? Trends Neurosci 2008 Oct;31(10):495-503.

117. Lenox RH, McNamara RK, Papke RL, et al. Neurobiology of lithium: an update. J Clin Psychiatry 1998;59 Suppl. 6:37-47.

118. Shiah I, Yatham L. GABA function in mood disorders: an update and critical review. Life Sci 1998;63(15):1289-303.

119. Petty F. Plasma concentrations of gamma-aminobutyric acid (GABA) and mood disorders: a blood test for manic depressive disease? Clin Chem 1994 Feb 1;40(2):296-302. 
120. Chuang D-M, Chen R-W, Chalecka-Franaszek E, et al. Neuroprotective effects of lithium in cultured cells and animal models of diseases. Bipolar Disord 2002;4(2):129-36.

121. Ahluwalia P, Grewaal DS, Singhal RL. Brain gabaergic and dopaminergic systems following lithium treatment and withdrawal. Prog Neuropsychopharmacol 1981;5(5-6):527-30.

122. Vargas C, Tannhauser M, Barros HMT. Dissimilar effects of lithium and valproic acid on GABA and glutamine concentrations in rat cerebrospinal fluid. Gen Pharmacol Vascular System 1998;30(4):6014.

123. Schloesser RJ, Huang J, Klein PS, et al. Cellular plasticity cascades in the pathophysiology and treatment of bipolar disorder. Neuropsychopharmacology 2008;33:110-33.

124. Manji HK, Lenox RH. The nature of bipolar disorder. J Clin Psychiatry 2000;61(Suppl. 13):4257.

125. Gould TD, Chen G, Manji HK. Mood stabilizer psychopharmacology. Clin Neurosci Res 2002;2(3-4):193-212.

126. Marmol F. Lithium: bipolar disorder and neurodegenerative diseases. Possible cellular mechanisms of the therapeutic effects of lithium. Prog Neuropsychopharmacol Biol Psychiatry 2008 Dec 12;32(8):1761-71.

127. Jope RS. Anti-bipolar therapy: mechanism of action of lithium. Mol Psychiatry 1999;4:117-28.

128. Montezinho LP, Mørk A, Duarte CB, et al. Effects of mood stabilizers on the inhibition of adenylate cyclase via dopamine D2-like receptors. Bipolar Disord 2007;9(3):290-7.

129. Jope RS. A bimodal model of the mechanism of action of lithium. Mol Psychiatry 1999;4(1):21-

5. 
130. Mann L, Heldman E, Bersudsky Y, et al. Inhibition of specific adenylyl cyclase isoforms by lithium and carbamazepine, but not valproate, may be related to their anti-depressant effect. Bipolar Disord 2009;11:885-96.

131. Ikonomov OC, Manji HK. Molecular mechanisms underlying mood stabilization in manicdepressive illness: the phenotype challenge. Am J Psychiatry 1999 Oct;156(10):1506-14.

132. Machado-Vieira R, Manji HK, Zarate Jr CA, et al. The role of lithium in the treatment of bipolar disorder: convergent evidence for neurotrophic effects as a unifying hypothesis. Bipolar Disord 2009 Jun;11 Suppl. 2:92-109.

133. Silverstone PH, McGrath BM. Lithium and valporate and their possible effects on the myoinositol second messenger system in healthy volunteers and bipolar patients. Int Rev Psychiatry 2009;21(4):414-23.

134. Calker Dv, Belmaker RH. The high affinity inositol transport system: implications for the pathophysiology and treatment of bipolar disorder. Bipolar Disord 2000;2(2):102-7.

135. Willmroth F, Drieling T, Lamla U, et al. Sodium-myo-inositol co-transporter (SMIT-1) mRNA is increased in neutrophils of patients with bipolar 1 disorder and down-regulated under treatment with mood stabilizers. Int J Neuropsychopharmacol 2007;10(1):63-71.

136. Deranieh RM, Greenberg ML. Cellular consequences of inositol depletion. Biochem Soc Trans 2009;37:1099-103.

137. Berridge MJ. Inositol trisphosphate and diacylglycerol as second messengers. Biochem $\mathbf{J}$ 1984;220:345-60.

138. Lenox RH, Wang L. Molecular basis of lithium action: integration of lithium-responsive signaling and gene expression networks. Mol Psychiatry 2003;8(2):135-44. 
139. Silverstone PH, McGrath BM, Kim H, et al. Bipolar disorder and myo-inositol: a review of the magnetic resonance spectroscopy findings. Bipolar Disord 2005 Feb;7(1):1-10.

140. Chen G, Hasanat KA, Bebchuk JM, et al. Regulation of signal transduction pathways and gene expression by mood stabilizers and antidepressants. Psychosom Med 1999 Sep-Oct;61(5):599-617.

141. Davanzo P, Thomas MA, Yue K, et al. Decreased anterior cingulate myo-inositol/creatine spectroscopy resonance with lithium treatment in children with bipolar disorder.

Neuropsychopharmacology 2001 Apr;24(4):359-69.

142. Moore GJ, Bebchuk JM, Parrish JK, et al. Temporal dissociation between lithium-induced changes in frontal lobe myo-inositol and clinical response in manic-depressive illness. Am J Psychiatry 1999 Dec;156(12):1902-8.

143. Chiu CT, Chuang DM. Neuroprotective action of lithium in disorders of the central nervous system. Zhong Nan Da Xue Xue Bao Yi Xue Ban 2011;36(6):461-76.

144. Zarate CA, Manji HK. Protein kinase $\mathrm{C}$ inhibitors: rationale for use and potential in the treatment of bipolar disorder. CNS Drugs 2009;23(7):569-82.

145. Hahn C-G, Friedman E. Abnormalities in protein kinase C signaling and the pathophysiology of bipolar disorder. Bipolar Disord 1999;1(2):81-6.

146. Szabo ST, Machado-Vieira R, Yuan P, et al. Glutamate receptors as targets of protein kinase C in the pathophysiology and treatment of animal models of mania. Neuropharmacology 2009 Jan;56(1):4755.

147. Manji HK, Etcheberrigaray R, Chen G, et al. Lithium decreases membrane-associated protein kinase C in hippocampus: selectivity for the $\alpha$ isozyme. J Neurochem 1993;61(6):2303-10. 
148. Lenox RH, Watson DG, Ellis J. Chronic lithium administration alters a prominent PKC substrate in rat hippocampus. Brain Res 1992;570:333-40.

149. Friedman E, Hoau Yan W, Levinson D, et al. Altered platelet protein kinase C activity in bipolar affective disorder, manic episode. Biol Psychiatry 1993;33(7):520-5.

150. Warsh JJ, Andreopoulos S, Li PP. Role of intracellular calcium signaling in the pathophysiology and pharmacotherapy of bipolar disorder: current status. Clin Neurosci Res 2004;4(3-4):201-13.

151. Berridge MJ, Bootman MD, Roderick HL. Calcium signalling: dynamics, homeostasis and remodelling. Nat Rev Mol Cell Biol 2003;4(7):517-29.

152. Carafoli E, Santella L, Branca D, et al. Generation, control, and processing of cellular calcium signals. Crit Rev Biochem Mol Biol 2001;36(2):107-260.

153. Berk M, Plein H, Ferreira D. Platelet glutamate receptor supersensitivity in major depressive disorder. Clin Neuropharmacol May/Jun 2001;24(3):129-32.

154. Berk M, Plein H, Belsham B. The specificity of platelet glutamate receptor supersensitivity in psychotic disorders. Life Sci 2000;66(25):2427-32.

155. Plein H, Berk M. Changes in the platelet intracellular calcium response to serotonin in patients with major depression treated with electroconvulsive therapy: state or trait marker status. Int Clin Psychopharmacol 2000;15(2):93-8.

156. Berk M, Kirchmann NH, Butkow N. Lithium blocks 45Ca2+ uptake into platelets in bipolar affective disorder and controls. Clin Neuropharmacol 1996;19(1):48-51.

157. Sourial-Bassillious N, Rydelius PA, Aperia A, et al. Glutamate-mediated calcium signaling: a potential target for lithium action. Neuroscience 2009;161(4):1126-34. 
158. Perova T, Kwan M, Li PP, et al. Differential modulation of intracellular Ca2+ responses in B lymphoblasts by mood stabilizers. Int J Neuropsychopharmacol 2010;13(06):693-702.

159. Crespo-Biel N, Camins A, Canudas AM, et al. Kainate-induced toxicity in the hippocampus: potential role of lithium. Bipolar Disord 2010;12(4):425-36.

160. Camins A, Crespo-Biel N, Junyent F, et al. Calpains as a target for therapy of neurodegenerative diseases: putative role of lithium. Curr Drug Metab 2009;10(5):433-47.

161. Chang K, Barnea-Goraly N, Karchemskiy A, et al. Cortical magnetic resonance imaging findings in familial pediatric bipolar disorder. Biol Psychiatry 2005 Aug;58(3):197-203.

162. Rajkowska G. Cell pathology in bipolar disorder. Bipolar Disord 2002;4:105-16.

163. Mielke K, Herdegen T. JNK and p38 stresskinases: degenerative effectors of signal-transductioncascades in the nervous system. Prog Neurobiol 2000;61(1):45-60.

164. Chen R-W, Qin Z-H, Ren M, et al. Regulation of c-Jun N-terminal kinase, p38 kinase and AP-1 DNA binding in cultured brain neurons: roles in glutamate excitotoxicity and lithium neuroprotection. J Neurochem 2003;84(3):566-75.

165. Chiu C-T, Chuang D-M. Molecular actions and therapeutic potential of lithium in preclinical and clinical studies of CNS disorders. Pharmacol Ther 2010;128(2):281-304.

166. Chen R-W, Chuang D-M. Long-term lithium treatment suppresses p53 and Bax expression but increases Bcl-2 expression. J Biol Chem 1999 Mar 5;274(10):6039-42.

167. Berk M, Conus P, Kapczinski F, et al. From neuroprogression to neuroprotection: implications for clinical care. Med J Aust 2010;193(4):S36-S40.

168. Ng F, Berk M, Dean OM, et al. Oxidative stress in psychiatric disorders: evidence base and therapeutic implications. Int J Neuropsychopharmacol 2008;11:851-76. 
169. Machado-Vieira R, Pivovarova NB, Stanika RI, et al. The Bcl-2 gene polymorphism rs956572AA increases inositol 1,4,5-trisphosphate receptor-mediated endoplasmic reticulum calcium release in subjects with bipolar disorder. Biol Psychiatry 2011;69(4):344-52.

170. Scola G, Kim HK, Young LT, et al. A fresh look at complex I in microarray data: clues to understanding disease-specific mitochondrial alterations in bipolar disorder. Biol Psychiatry. 2012 Jul 28.

171. Maurer IC, Schippel P, Volz H-P. Lithium-induced enhancement of mitochondrial oxidative phosphorylation in human brain tissue. Bipolar Disord 2009;11(5):515-22.

172. Eskandari M, Fard J, Hosseini M-J, et al. Glutathione mediated reductive activation and mitochondrial dysfunction play key roles in lithium induced oxidative stress and cytotoxicity in liver. Biometals Oct;25(5):863-73.

173. Berk M, Ng F, Dean O, et al. Glutathione: a novel treatment target in psychiatry. Trends Pharmacol Sci 2008;29(7):346-51.

174. Frey BN, Martins MR, Petronilho FC, et al. Increased oxidative stress after repeated amphetamine exposure: possible relevance as a model of mania. Bipolar Disord 2006;8(3):275-80.

175. Andreazza AC, Kapczinski F, Kauer-Sant'Anna M, et al. 3-Nitrotyrosine and glutathione antioxidant system in patients in the early and late stages of bipolar disorder. J Psychiatry Neurosci 2009;34(4):263-71.

176. Andreazza AC, Shao L, Wang J-F, et al. Mitochondrial complex I activity and oxidative damage to mitochondrial proteins in the prefrontal cortex of patients with bipolar disorder. Arch Gen Psychiatry 2010 Apr 1;67(4):360-8.

177. Andreazza AC, Cassini C, Rosa AR, et al. Serum S100B and antioxidant enzymes in bipolar patients. J Psychiatr Res 2007;41(6):523-9. 
178. Cecil KM, DelBello MP, Morey R, et al. Frontal lobe differences in bipolar disorder as determined by proton MR spectroscopy. Bipolar Disord 2002;4(6):357-65.

179. Frey BN, Valvassori SS, Reus GZ, et al. Effects of lithium and valproate on amphetamineinduced oxidative stress generation in an animal model of mania. J Psychiatry Neurosci 2006 Sep;31(5):326-32.

180. Machado-Vieira R, Andreazza AC, Viale CI, et al. Oxidative stress parameters in unmedicated and treated bipolar subjects during initial manic episode: a possible role for lithium antioxidant effects. Neurosci Lett 2007;421(1):33-6.

181. Cunha ABM, Frey BN, Andreazza AC, et al. Serum brain-derived neurotrophic factor is decreased in bipolar disorder during depressive and manic episodes. Neurosci Lett 2006;398(3):215-9.

182. Tramontina JF, Andreazza AC, Kauer-Sant'Anna M, et al. Brain-derived neurotrophic factor serum levels before and after treatment for acute mania. Neurosci Lett 2009;452(2):111-3.

183. Einat H, Manji HK, Einat H, et al. Cellular plasticity cascades: genes-to-behavior pathways in animal models of bipolar disorder. Biol Psychiatry 2006 Jun 15;59(12):1160-71.

184. Rybakowski JK, Suwalska A. Excellent lithium responders have normal cognitive functions and plasma BDNF levels. Int J Neuropsychopharmacol 2010;13:617-22.

185. Vidal F, de Araujo WM, Cruz AL, et al. Lithium reduces tumorigenic potential in response to EGF signaling in human colorectal cancer cells. Int J Oncol 2011;38(5):1365-73.

186. Cameron AR, Anil S, Sutherland E, et al. Zinc-dependent effects of small molecules on the insulin-sensitive transcription factor FOXO1a and gluconeogenic genes. Metallomics 2010;2(3):195-203. 
187. Manji HK, Moore GJ, Chen G. Lithium up-regulates the cytoprotective protein bcl-2 in the CNS in vivo: a role for neurotrophic and neuroprotective effects in manic depressive illness. J Clin Psychiatry 2000;61(Suppl. 9):82-96.

188. Lien R, Flaisher-Grinberg S, Cleary C, et al. Behavioral effects of Bcl-2 deficiency: implications for affective disorders. Pharmacol Rep 2008 Jul-Aug;60(4):490-8.

189. Chang YC, Rapoport SI, Rao JS. Chronic administration of mood stabilizers upregulates BDNF and bcl-2 expression levels in rat frontal cortex. Neurochem Res 2009 Mar;34(3):536-41.

190. Ghribi O, Herman MM, Spaulding NK, et al. Lithium inhibits aluminum-induced apoptosis in rabbit hippocampus, by preventing cytochrome $\mathrm{c}$ translocation, Bcl-2 decrease, Bax elevation and caspase-3 activation. J Neurochem 2002;82(1):137-45.

191. Beaulieu J-M, Sotnikova TD, Yao W-D, et al. Lithium antagonizes dopamine-dependent behaviors mediated by an AKT/glycogen synthase kinase 3 signaling cascade. Proc Natl Acad Sci U S A 2004 Apr 6;101(14):5099-104.

192. Prickaerts J, Moechars D, Cryns K, et al. Transgenic mice overexpressing glycogen synthase kinase 3ß: a putative model of hyperactivity and mania. J Neurosci 2006;26(35):9022-9.

193. Klein E, Melton DA. A molecular mechanism for the effect of lithium on development. Proc Nat Acad Sci 1996;93(16):8455-9.

194. Li X, Friedman AB, Zhu W, et al. Lithium regulates glycogen synthase kinase-3 $\beta$ in human peripheral blood mononuclear cells: implication in the treatment of bipolar disorder. Biol Psychiatry 2007;61(2):216-22.

195. Tajes M, Yeste-Velasco M, Zhu X, et al. Activation of Akt by lithium: pro-survival pathways in aging. Mech Ageing Dev 2009;130:253-61. 
196. Freland L, Beaulieu J-M. Inhibition of GSK3 by lithium, from single molecules to signaling networks. Front Mol Neurosci 2012; 5: 14.

197. Rowe MK, Wiest C, Chuang D-M. GSK-3 is a viable potential target for therapeutic intervention in bipolar disorder. Neuroscience Biobehav Rev 2007;31(6):920-31.

198. Gould TD, Einat H, Bhat R, et al. AR-A014418, a selective GSK-3 inhibitor, produces antidepressant-like effects in the forced swim test. Int J Neuropsychopharmacol 2004;7:387-90.

199. Silva R, Mesquita AR, Bessa J, et al. Lithium blocks stress-induced changes in depressive-like behavior and hippocampal cell fate: the role of glycogen-synthase-kinase-3 $\beta$. Neuroscience 2008;152(3):656-69.

200. Wada A. Lithium and neuropsychiatric therapeutics: neuroplasticity via glycogen synthase kinase-3 $\beta$, $\beta$-catenin, and neurotrophin cascades. J Pharmacol Sci 2009;110(1):14-28.

201. Maiuri MC, Zalckvar E, Kimchi A, et al. Self-eating and self-killing: crosstalk between autophagy and apoptosis. Nat Rev Mol Cell Biol 2007;8(9):741-52.

202. Meléndez A, Neufeld TP. The cell biology of autophagy in metazoans: a developing story. Development 2008 Jul 15;135(14):2347-60.

203. Sarkar S, Krishna G, Imarisio S, et al. A rational mechanism for combination treatment of Huntington's disease using lithium and rapamycin. Hum Mol Genet 2008;17(2):170-8.

204. Sarkar S, Floto RA, Berger Z, et al. Lithium induces autophagy by inhibiting inositol monophosphatase. J Cell Biol 2005 Sep 26;170(7):1101-11.

205. Heiseke A, Aguib Y, Schatzl HM. Autophagy, prion infection and their mutual interactions. Curr Issues Mol Biol 2009;12:87-98. 
206. Camins A, Verdaguer E, Junyent F, et al. Potential mechanisms involved in the prevention of neurodegenerative diseases by lithium. CNS Neurosci Ther 2009;15(4):333-44.

207. Dean OM, Bush AI, Berk M. Translating the rosetta stone of N-acetylcysteine. Biol Psychiatry 2012;71(11):935-6.

\section{Malhi}

In all 3 figures, change font size to 8 pt Helvetica or Arial

\section{Figure 1:}

Change stabilisation to stabilization

Change Altered Cognitive Functioning to Altered cognitive functioning

Change gray to grey

Change Glutamate and Dopamine to glutamate and dopamine

Change Second Messenger System to second messenger system

Change Inositol to inositol

Change defense to defence

Change Intracellular Changes to intracellular changes

Close-up and spaces between $\uparrow \downarrow$ and the first letter of a word

\section{Figure 2:}




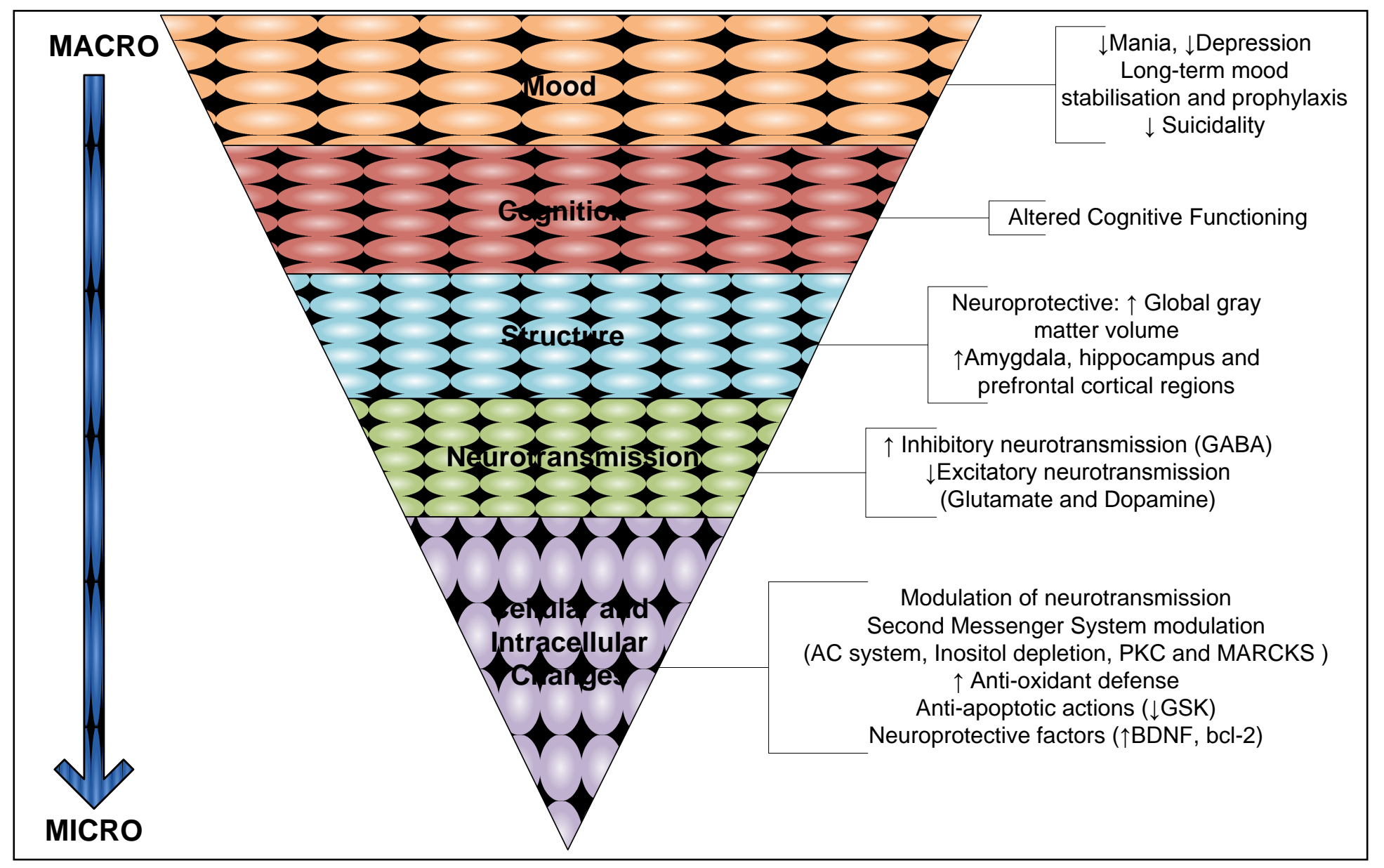

